\title{
OIKOS
}

\section{Resource composition mediates the effects of intraspecific variability in nutrient recycling on ecosystem processes}

\begin{tabular}{|c|c|}
\hline Journal: & Oikos \\
\hline Manuscript ID & OIK-03787.R2 \\
\hline Wiley - Manuscript type: & Research \\
\hline Date Submitted by the Author: & $\mathrm{n} / \mathrm{a}$ \\
\hline Complete List of Authors: & $\begin{array}{l}\text { Evangelista, Charlotte; Evolution \& Biological Diversity } \\
\text { Lecerf, A. } \\
\text { Britton, Robert; Bournemouth University, School of Applied Sciences } \\
\text { Cucherousset, Julien; CNRS, UMR } 5174 \text { EDB }\end{array}$ \\
\hline Keywords: & nutrient excretion, ecosystem functioning, trophic specialization \\
\hline Abstract: & $\begin{array}{l}\text { Despite the growing evidence for individual variation in trophic niche within } \\
\text { populations, its potential indirect effects on ecosystem processes remains } \\
\text { poorly understood. Here, we first quantified the level of intraspecific trophic } \\
\text { variability in } 11 \text { wild populations of the omnivorous fish Lepomis gibbosus. } \\
\text { Outputs from stomach content and stable isotope analyses revealed that } \\
\text { the degree of trophic specialization and trophic positions were highly } \\
\text { variable between and within these wild populations. There was } \\
\text { intrapopulation variation in trophic position of more than one trophic level, } \\
\text { suggesting that individuals consumed a range of plant and animal } \\
\text { resources. We then experimentally assessed how intraspecific trophic } \\
\text { variability modulates consumer-mediated nutrient effects on relevant } \\
\text { processes of ecosystem functioning. This was completed by manipulating } \\
\text { intraspecific trophic variability through changes in the degree of } \\
\text { specialization (i.e. specialist, intermediate and generalist) and using three } \\
\text { food sources varying in nutrient quality (e.g. plant material, macro- } \\
\text { invertebrate and fish meat). Food items were used individually (specialist } \\
\text { individuals) or in combination (intermediate and generalist individuals) } \\
\text { leading to the use of seven dietary experimental treatments. Results } \\
\text { indicated that intraspecific variability in growth and nitrogen excretion } \\
\text { rates were more related to the composition of the diet rather than the } \\
\text { degree of specialization, and increased with the trophic position of the diet } \\
\text { consumed. In contrast, phosphorous excretion rates did not change in } \\
\text { accordance with these variables. We subsequently used microcosms in } \\
\text { which excretory products were introduced and showed that critical } \\
\text { ecosystem functions, such as primary production and community } \\
\text { respiration, were affected by the variability in excretory products caused by } \\
\text { the manipulation of intraspecific trophic variability, and this effect was } \\
\text { biomass-dependent. These results highlight the importance of the } \\
\text { interaction between individual trophic niche and consumer-mediated } \\
\text { nutrient recycling in modulating ecosystem processes. }\end{array}$ \\
\hline
\end{tabular}


Page 1 of 48 \begin{tabular}{l} 
Oikos \\
$\qquad \begin{array}{r}\text { SCHOLARONE } \\
\text { Manuscripts }\end{array}$ \\
\hline
\end{tabular}

Page 1 of $48 \begin{aligned} & \text { Oikos } \\ & \qquad \begin{array}{r}\hline \text { SCHOLARONE } \\ \hline\end{array} \\ & \text { Manuscripts }\end{aligned}$

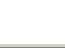
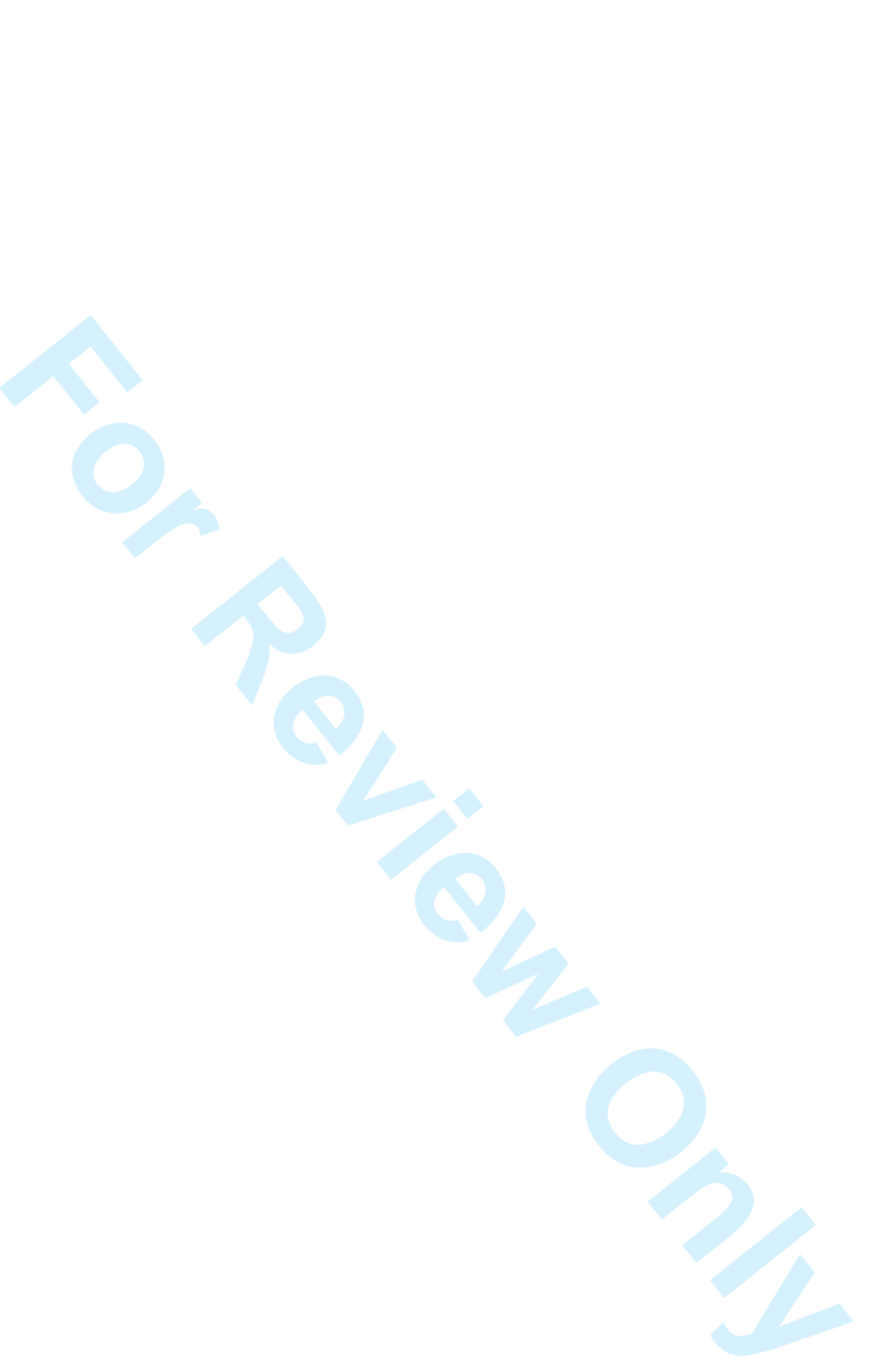
1 Resource composition mediates the effects of intraspecific variability in nutrient

2 recycling on ecosystem processes

3

4

Charlotte Evangelista, Antoine Lecerf, J. Robert Britton and Julien Cucherousset

7

8 C. Evangelista (charlotte.evangelista0@gmail.com) and A. Lecerf, EcoLab (Laboratoire Ecologie 9 Fonctionnelle et Environnement), Univ. de Toulouse, CNRS, INP, UPS, Toulouse, France. - CE. and 10 J. Cucherousset, CNRS, Univ. Toulouse III Paul Sabatier, ENFA, UMR 5174 EDB (Laboratoire 11 Evolution \& Diversité Biologique), 118 route de Narbonne, F-31062 Toulouse, France. - J.R. Britton, 12 Department for Life \& Environmental Sciences, Faculty of Science and Technology, Bournemouth 13 University, Poole, Dorset BH12 5BB, UK. 


\section{Abstract}

Despite the growing evidence for individual variation in trophic niche within populations, its potential indirect effects on ecosystem processes remains poorly understood. In particular, few studies have investigated how intraspecific trophic variability can modulate the effects of consumers on ecosystems through potential changes in nutrient excretion rates. Here, we first quantified the level of intraspecific trophic variability in 11 wild populations of the omnivorous fish Lepomis gibbosus. Outputs from stomach content and stable isotope analyses revealed that the degree of trophic specialization and trophic positions were highly variable between and within these wild populations. There was intrapopulation variation in trophic position of more than one trophic level, suggesting that individuals consumed a range of plant and animal resources. We then experimentally manipulated intraspecific trophic variability to assess how it can modulate consumer-mediated nutrient effects on relevant processes of ecosystem functioning. Specifically, three food sources varying in nutrient quality (e.g. plant material, macro-invertebrate and fish meat) were used individually or in combination to simulate seven diet treatment. Results indicated that intraspecific variability in growth and nitrogen excretion rates were more related to the composition of the diet rather than the degree of specialization, and increased with the trophic position of the diet consumed. We subsequently used microcosms and showed that critical ecosystem functions, such as primary production and community respiration, were affected by the variability in excretory products, and this effect was biomass-dependent. These results highlight the importance of considering variation within species to better assess the effects of individuals on ecosystems and, more specifically, the effects of consumer-mediated nutrient recycling because the body size and the trophic ecology of individuals are affected by a large spectrum of natural and humaninduced environmental changes. 


\section{INTRODUCTION}

Within populations, trophic niches vary among individuals (e.g. Bolnick et al. 2003), which can have strong consequences on population dynamics and community structure (Araújo et al. 2011). Intraspecific trophic variability may also alter the extent to which and how species influence ecosystem functioning (Harmon et al. 2009), but the mechanisms underpinning these changes remain relatively unknown. Consumers can exert top-down control through resource consumption, potentially causing cascading effects to lower trophic levels via density-mediated interactions (Pace et al. 1999). Simultaneously, they selectively sequester consumed nutrients into their body to meet their requirements for growth and reproduction (Sterner and Elser 2002). Excess nutrients and metabolic by-products are released via excretion and egestion, potentially enhancing the "bottom-up" control of ecosystem processes (Glaholt and Vanni 2005, Knoll et al. 2009). Consequently, consumer-mediated nutrient recycling is an essential process within ecosystem dynamics, and predicting patterns in variation of excretion rates is relevant to better understanding the effects of consumers on ecosystem functioning (Taylor et al. 2015).

Early studies on consumer-mediated nutrient recycling have uncovered substantial interspecific variations in rates of nitrogen and phosphorus excretion, ultimately depending on elemental imbalance between consumers and their resources (Vanni et al. 2002, McIntyre et al. 2007, Small et al. 2011). High variations in excretion rates among conspecific individuals have also been reported (Villéger et al. 2012, El-Sabaawi et al. 2015a), with this potentially affecting ecosystem processes (Bassar et al. 2010, Taylor et al. 2012, El-Sabaawi et al. 2015b). Intraspecific variability in excretion rates is difficult to predict, as it might result from differences in both metabolic rate and trophic niche among individuals (Vrede et al. 2011). Intraspecific trophic variability may create variations in nutrient excretion rates of consumers 
65

by acting on the degree of specialization and the quality of the resource consumed, with the two factors potentially interacting. However, the relative importance of these two parameters is poorly understood, notably because trophic specialization and diet composition are difficult to assess in wild populations (e.g. Bolnick et al. 2003). By foraging on a single prey, specialist individuals should display strongest nutrient imbalance with their resources compared to generalists, particularly if the mismatch is large (Frost et al. 2005). Therefore, individuals specialized on nutrient-rich resources are expected to release nutrient at higher rate than individuals foraging on nutrient-poor resources (Sterner and Elser 2002). In addition, specialist individuals are also predicted to have superior fitness than generalists (Bolnick et al. 2003). Alternatively, generalists might maximize their fitness by foraging on a resource assemblage made of nutritionally complementary resources (DeMott 1998). Diet mixing, by altering resource-consumer elemental imbalance, may lead to antagonistic or synergistic effects on nutrient excretion rates in generalist individuals.

Fishes are important regulators of biogeochemical cycles in freshwater ecosystems, due to their excretion of potentially limiting nutrients which are essential to support primary producers and heterotrophic microbes (Small et al. 2011, Capps and Flecker 2013). Fish diet composition varies considerably across trophic levels, ranging from herbivores consuming plant, phytoplankton and algal detritus to apex-predators consuming vertebrates, and including omnivores that feed across multiple trophic levels. These trophic groups often display striking differences in nutrient excretion rates, which are apparent at both the interand intraspecific levels (Villéger et al. 2012). Fishes are relevant examples of animals whose populations show considerable intraspecific trophic variability (Smith and Skúlason 1996, Bolnick et al. 2003), with individuals within populations often exhibiting a diversity of dietary strategies, from generalist to specialist (Quevedo et al. 2009, Svanbäck et al. 2015). For instance, the ratio of nitrogen and phosphorus excreted by Grizzard shad (Dorosoma 
90

91

cepedianum) was found to vary over nearly an order of magnitude among individuals, with dietary shifts suggested as mainly being responsible for this intraspecific variability in nutrient excretion rates (Pilati and Vanni, 2007). This highlights the requirement to account for intraspecific trophic variability to better understand how fish can mediate nutrient recycling and, ultimately, affect the functioning of aquatic ecosystems.

The aim of our study was to quantify the effects of intraspecific trophic variability on consumer-mediated nutrient recycling and determine its potential consequences on relevant ecosystem processes. We selected the omnivorous fish Lepomis gibbosus (Linnaeus, 1758) as model species since it is an opportunistic omnivore that varies in its intensity of feeding on animals (e.g. macro-invertebrates and fish) and plant material (e.g. algae, macrophytes, windspread terrestrial seeds and detritus) (García-Berthou and Moreno-Amich 2000, Rezsu and Specziar 2006). It also displays a high level of intraspecific trophic variability (McCairns and Fox 2004, Bhagat et al. 2011). Using field and experimental approaches, the study was conducted in three phases: a field survey to quantify trophic specialization and diet composition in wild populations, a feeding experiment designed to test how specialization and diet composition influenced nutrient excretion rates and growth rates of fish, and a laboratory microcosm experiment used to assess effects of intraspecific variability of nutrient excretion rates on ecosystem processes. Stomach content and stable isotope analyses (SCA and SIA, respectively) were used in conjunction and performed on individuals of L. gibbosus originating from 11 lakes to determine extent of population heterogeneity as revealed by trophic specialization and difference in trophic position. In the laboratory, individuals of $L$. gibbosus were provided with diet differing in the number and type of food items to test for differences in nutrient excretion rates between specialists and generalists (Frost et al. 2005). We hypothesized that, independently of the diet quality, high level of specialization would lead to higher range of nutrient excretion rates within a population, given that diet diversity 
115

116

117

118

119

120

121

122

123

124

125

126

127

128

129

130

131

132

133

134

135

136

137

138

139

enables generalist individuals to cope better with nutrient imbalances than specialists (Frost et al. 2005). We also predicted that individuals feeding on nutrient-rich resource would excrete more nutrients (Sterner and Elser 2002, McIntyre and Flecker 2010). Finally, microbial microcosms supplied with excretion products released by fish during the feeding experiment were used to assess how intraspecific variation in nutrient excretion rates affected wholesystem metabolism and litter decomposition. Increased nutrient availability through consumer recycling should stimulate rates of both autotrophic (primary production) and heterotrophic (respiration and litter decomposition) processes. Moreover, as decomposers are better competitors for nutrient resources than producers (Currie and Kalff 1984), it is also possible that heterotrophic processes respond more to fish excretion products addition than autotrophic processes.

\section{MATERIAL \& METHODS}

Field survey of intraspecific trophic variability

To assess inter-individual variability in the trophic niches of L. gibbosus, populations were sampled from 11 lakes that were former gravel pits in the flood plain of the Garonne River, France (Zhao et al. 2016). Sampling was completed in similar weather conditions (21 to $24^{\circ} \mathrm{C}$, mixed cloud cover) between mid-September and mid-October 2012 by electrofishing along the littoral shoreline (Evangelista et al. 2015). To reduce biases between lakes in SCA related to the feeding period of consumers, one lake was sampled per day and electrofishing was conducted during the same period of time in each lake (between 1:00 to 3:30 pm). Captured individuals were immediately euthanized using an overdose of anaesthetic, stored on ice and frozen in the laboratory $\left(-20^{\circ} \mathrm{C}\right)$ until subsequent processing. After defrosting, a subsample of 28 adult individuals (mean fork length $=79.0 \mathrm{~mm} \pm 1.4 \mathrm{SE}$ ) was selected in each population 
140 when available $($ mean $=27.6 \pm 1.2$ individuals per population; Table 1$)$, measured for fork

141 length $(\mathrm{FL} \pm 1 \mathrm{~mm})$ and weighted $(\mathrm{W} \pm 0.1 \mathrm{~g})$. Stomach contents were dissected under a

142 microscope and prey items were counted and identified to the lowest taxonomic level (mostly

143 family level) for SCA (Appendix A). Importantly, although present in stomach contents, plant

144 debris (i.e. wind-spread seeds, algae, terrestrial detritus) could not be counted and were thus

145 excluded from SCA. Whilst stomach content data provide information on the taxonomy of

146 prey items, it has important limitations arising from their representation of the diet of an

147 individual as a single snapshot (i.e. several hours only); it can also underestimate the

148 consumption of highly digestible prey. Consequently, the use of a complementary, temporally

149 integrative approach to measure of intraspecific trophic variability was required, with this

150 provided by SIA (Bolnick et al. 2003, Layman et al. 2012). The SIA was performed on the

151 same individuals to assess trophic variability over a longer time period than SCA (Layman et

152 al. 2012). Specifically, dorsal muscle samples were collected for stable isotope analyses of

153 carbon $\left(\delta^{13} \mathrm{C}\right.$ value $)$ and nitrogen $\left(\delta^{15} \mathrm{~N}\right.$ value $)$ which provide information on the origin of the

154 resource consumed (e.g. littoral versus pelagic) and the trophic position of the consumers, 155 respectively (Post 2002). Concomitantly, the putative prey resources of the fish were sampled 156 from the littoral and pelagic habitats of the lakes with a pond net and with a $100-\mu \mathrm{m}$ mesh net 157 and an Ekman dredge, respectively (Appendix A). Prior to analyses, all stable isotope samples 158 were oven dried $\left(48 \mathrm{~h}\right.$ at $\left.60^{\circ} \mathrm{C}\right)$, ground in a fine powder and subsequently analyzed at the 159 Cornell Isotope Laboratory (Ithaca, New York, USA). The analytical precision for all 160 samples, calculated as the standard deviation of an internal mink standard, was 0.11 and 0.12 $161 \%$ for $\delta^{13} \mathrm{C}$ and $\delta^{15} \mathrm{~N}$ values respectively.

162

163

Experimental approaches

164

Collection and rearing of experimental fish 
165 Based on the field results, L. gibbosus were then collected from a single lake (area $=20.8$ ha, 166 mean depth $=3.7 \mathrm{~m}$ ) whose trophic outputs indicated an intermediate level of trophic 167 specialization, with a relatively large spectrum of prey consumed. On October $3^{\text {rd }} 2013,81$ 168 individuals (FL: 65 to $75 \mathrm{~mm}$ ) were captured in the littoral habitat using a seine net (5-mm 169 mesh size) and then acclimated to laboratory conditions in three tanks (200 L, photoperiod: 12/12 h; water temperature: 17 to $18.5^{\circ} \mathrm{C}$ ) over six weeks. The individual fish were fed $a d$ libitum with commercial red maggots (Diptera) until the beginning of the experiment to minimize background variability in body elemental composition among individuals. During the mid-acclimation period, L. gibbosus were anaesthetized with eugenol $\left(0.1 \mathrm{~mL} . \mathrm{L}^{-1}\right)$, measured for initial fork length $\left(\mathrm{FL}_{\mathrm{i}} \pm 1 \mathrm{~mm}\right)$, weighed $\left(\mathrm{W}_{\mathrm{i}} \pm 0.1 \mathrm{~g}\right)$, individually tagged with passive integrated transponder (FDX PIT-tags, Oregon RFID, Portland, Oregon), and released into the 200 L-tanks after recovery in well-aerated water. At the end of the acclimation period, 48 individuals of the similar length range and age class were selected $\left(\mathrm{FL}_{\mathrm{i}}\right.$ range: $79-98 \mathrm{~mm}$, mean $\pm \mathrm{SE} 89.0 \pm 0.8$; age $1+$ and $2+$ years; Evangelista et al. unpublished data) for use in the experiment. The use of fish of similar lengths and ages limited the potential effects of ontogeny on the experimental data. The fish were transferred individually to 48 tanks filled with 50-L of dechlorinated tap water. Each tank was equipped with a filtration system, a plastic plant and a shelter. The 48 experimental units were distributed among 6 vertical shelving units ( 6 blocks of 8 treatments). comprised of one, two, or three food items in order to simulate three levels of decreasing trophic specialization. Using the diet data from experiment, trophic specialization was

\section{Effects of intraspecific trophic variability on nutrient recycling rates}

During the laboratory experiment (9 weeks), fish were provided with one of three diets that calculated as the diet overlap between an individual $\mathrm{i}$ and all individuals used in the 
190

191

192

193

194

195

experiment (i.e. the population) using the proportional similarity index $\mathrm{PS}_{\mathrm{i}}$, calculated following Bolnick et al. (2002) (Appendix B). PS $\mathrm{i}_{\mathrm{i}}$ varies from 0 (no overlap) to 1 (total overlap). Here, $\mathrm{PS}_{\mathrm{i}}$ ranged from 0.33 for specialist individuals and 0.99 for generalist individuals, and the $\mathrm{PS}_{\mathrm{i}}$ of intermediate individuals was 0.66 (Fig. 1). The items represented vegetable matter (cooked white rice $[\mathrm{R}]$ ), macro-invertebrates (chironmonid larvae $[\mathrm{C}]$ ) and fish (grounded rainbow trout dorsal muscle with skin $[F]$ ). These items were used as they represented the three different reported trophic levels of L. gibbosus prey (García-Berthou and Moreno-Amich 2000) and cover a broad range of elemental composition (Fig. 1). White rice was selected as a plant-based source because it is readily available in a standardized size and quality and could mimic the quality of plant seeds and angling bait that are consumed by $L$. gibbosus. Rice was cooked to obtain a texture similar to the texture of plant seeds and angling bait after they have spent several days in water. Where mixtures of two and three items were used as the diet, their total wet mass partitioned equally among the items. The diets were hand-fed to L. gibbosus using a daily ration of $3 \%$ of individual initial body mass (Glaholt and Vanni 2005). Mixed diets (i.e. intermediate and generalist) were homogenized manually to reduce potential bias towards the consumption of potential preferred item(s), while also maintaining item size.

The experimental design composed of seven treatments (Fig. 1): three types of specialists feeding on a single diet item (cooked rice [R], chironomid larvae [C] or fish meat $[\mathrm{F}]$ ), three types of intermediates feeding on a mixture of two diet items (cooked rice $\times$ chironomid larvae $[\mathrm{RC}]$, cooked rice $\times$ fish meat $[\mathrm{RF}]$ or chironomid larvae $\times$ fish meat $[\mathrm{CF}]$, and one generalist type feeding on an even mixture of all the diet items (cooked rice $x$ chironomid larvae $\times$ fish meat $[\mathrm{RCF}])$. There were six replicates for each specialist and intermediate treatment, and twelve replicates for the generalist treatment to fully account for higher variability in the mixture that arose from the homogenization of the dietary items. The 
215 individual L. gibbosus were randomly assigned to each treatment and there was no significant

216 difference in the mean $\mathrm{W}_{\mathrm{i}}$ and $\mathrm{FL}_{\mathrm{i}}$ between treatments at the start of the experiment

217 (ANOVA, $P=0.178$ and $P=0.07$ respectively).

218 Ammonium $\left(\mathrm{N}^{-\mathrm{NH}_{4}}{ }^{+}\right.$, hereafter referred to as $\left.\mathrm{N}\right)$ and soluble reactive phosphorus (SRP, hereafter referred to as P) excretion rates of $L$. gibbosus were quantified at the beginning of the experiment, just prior to the individuals being transferred in their

221

222

223

224

225

226

227

experimental tanks (November $15^{\text {th }} 2013$ ) and at the end of the experiment (January $16^{\text {th }}$ 2014). Per capita excretion rates (ER, hereafter referred to as 'excretion rate'; $\mu \mathrm{mol}$ ind. $^{-1} \mathrm{~h}^{-1}$ ) were quantified, following Vanni et al. (2002). Two hours after feeding, L. gibbosus were incubated individually for $1.5 \mathrm{~h}$ in a plastic bag containing $0.8 \mathrm{~L}$ of spring water (Glaholt and Vanni 2005; see details in Appendix B). Filtered water samples (80 mL filtered using Whatman GF/C, pore size $1.2 \mu \mathrm{m}$ ) were analyzed for N and SRP concentrations (Appendix B) and excretion rates of $\mathrm{N}$ and $\mathrm{P}\left(\mu \mathrm{mol}\right.$ ind. $\left.{ }^{-1} \mathrm{~h}^{-1}\right)$ were calculated for each individual following Vanni et al. (2002):

$$
\mathrm{ER}_{\mathrm{I}}=\left(\left([\mathrm{I}]_{\text {ind }}-[\mathrm{I}]_{\text {control }}\right) \times \mathrm{V}\right) / \mathrm{t}
$$

where $[\mathrm{I}]_{\text {ind }}$ and $[\mathrm{I}]_{\text {control }}$ are the molar concentration $\left(\mu \mathrm{mol} \mathrm{L} \mathrm{L}^{-1}\right)$ of the element I observed for fish and control, respectively, $\mathrm{V}$ is the volume (L) of spring bottled water in the plastic bag and $\mathrm{t}$ is the duration of the incubation (h) (Apendix B). For each block, one control bag filled with bottled water but without fish was used to assess background levels of ammonium and phosphorus at the end of the excretion trials. Importantly, these excretion trials were performed every two weeks over the whole experimental period to renew the microcosm water but without quantifying nutrient concentrations (see details below). At the end of the experiment, after the final excretion trial, L. gibbosus were euthanized using an overdose of anesthetic and weighed $\left(\mathrm{W}_{\mathrm{f}} \pm 0.1 \mathrm{~g}\right)$. Specific growth rate $\left(\mathrm{SGR} ; \%\right.$ week $\left.^{-1}\right)$ during the experiment was calculated as follows: 


$$
\mathrm{SGR}=100 \times\left(\ln \mathrm{W}_{\mathrm{f}}-\ln \mathrm{W}_{\mathrm{i}}\right) / \mathrm{t}
$$

241 where $t$ is the duration of the experiment ( 9 weeks).

242

\section{Effects of consumer-mediated nutrient recycling on ecosystem functioning}

244

245

Laboratory microcosms were used to assess the indirect effects of intraspecific trophic variability on aquatic ecosystem processes through changes in fish-mediated nutrient recycling. Microcosms were used to mimic relevant processes occurring in the benthic littoral zone occupied by L. gibbosus in the wild, because the ability to measure these processes insitu is inherently challenging. Microcosms $(\mathrm{n}=54,48$ for each experimental individual and 6 for each control) consisted of one-liter cylindrical containers initially filled with $0.25 \mathrm{~L}$ of dechlorinated water and initiated with $0.5 \mathrm{~L}$ unfiltered lake water containing an inoculum of autotrophic and heterotrophic microorganisms. They were supplied with oak (Quercus robur L.) leaf litter collected at abscission and cut into leaf discs of $15 \mathrm{~mm}$ diameter using a cork borer. Each microcosm received a set of 10 leaf discs that were previously weighed to the nearest $0.1 \mathrm{mg}$ (mean $=164.83 \mathrm{mg} \pm 0.41 \mathrm{SE})$. Microbial communities were allowed to develop from November $7^{\text {th }}$ to $22^{\text {th }} 2013$ before the microcosms were gently emptied until there was $0.1 \mathrm{~L}$ of water left in order to avoid losing particulate matter that remained on the bottom of the microcosm. Microcosms were then immediately supplied with $0.8 \mathrm{~L}$ of water containing fish excretory products (or clean spring water for controls) from fish excretion trials of $22^{\text {th }}$ November 2013. During the experiment (54 days), microcosm water was renewed on four occasions with excretion products from trials spaced two weeks apart (i.e. $22^{\text {th }}$ November, $5^{\text {th }}$ and $19^{\text {th }}$ December, and $2^{\text {nd }}$ January 2014), and following the same procedure as described above. Microcosms were exposed to a $12 \mathrm{~h}$ light : $12 \mathrm{~h}$ dark photoperiod (mean instantaneous light intensity $=252.1 \mu \mathrm{mol} \mathrm{m} \mathrm{m}^{-2} \mathrm{~s}^{-1} \pm 10.3 \mathrm{SE}$ ) at the laboratory temperature $\left(17.0-18.5^{\circ} \mathrm{C}\right)$. They were assigned to the 48 experimental 
265 individuals and replicates were arranged in six blocks, corresponding to the level and the side 266 (left or right) of a three-shelf unit.

267 Whole-microcosm metabolism, the standing biomass of algae and leaf-decaying fungi, 268 litter mass loss rate and particulate nutrient concentration were assessed at the end of the 269 experiment. The side of each microcosm was gently brushed to remove the biofilm, content 270 was homogenized with blender and $0.06 \mathrm{~L}$ of water was filtered onto a Whatman GF/C filter. 271 Filters were then oven-dried $\left(60^{\circ} \mathrm{C}\right.$ for $\left.48 \mathrm{~h}\right)$ and used to quantify the amounts of particulate 272 nutrients ( $\mathrm{N}$ and $\mathrm{P} ; \mu \mathrm{mol})$. Gross primary productivity (GPP) and community respiration (CR) 273 were quantified using diurnal changes in oxygen levels (following Harmon et al. 2009). Using an optical DO probe, Dissolved oxygen (DO) was measured (optical DO probe; Hach HQ10, LDO) right after the light was switched on ( $\mathrm{t}_{0}$, sunrise $)$, and after $12 \mathrm{~h}\left(\mathrm{t}_{1}\right.$, sunset $)$ and $24 \mathrm{~h}\left(\mathrm{t}_{2}\right.$, following sunrise) to capture day-time and night-time variations. Daily CR and GPP (mg $\left.\mathrm{O}_{2}\right)$ was calculated as follows:

$$
\mathrm{CR}=\left(\mathrm{DO}_{\mathrm{t} 1-\mathrm{t} 2}\right) \times 2 \times \mathrm{V} \text { and } \mathrm{GPP}=\left(\mathrm{CR}+\mathrm{DO}_{\mathrm{t} 1-\mathrm{t} 0}\right) \times \mathrm{V}
$$

where $\mathrm{V}$ was the volume of water in microcosms $(0.9 \mathrm{~L})$. Total algal standing biomass $(\mu \mathrm{g})$ was assessed based on the chlorophyll-a concentration and a subsample of $0.1 \mathrm{~L}$ of homogenized water was filtered onto a Whatman GF/F filter (pore size $0.45 \mu \mathrm{m}$ ) stored in the dark at $-20^{\circ} \mathrm{C}$ until analysis. Chlorophyll-a was extracted in $90 \%$ acetone for $24 \mathrm{~h}$ and its concentration was determined with a spectrophotometer (HITACHI U-1100) following Steinman et al. (2006). Before quantifying algal biomass, the leaf discs were gently removed from the microcosms, washed with deionized water, and freeze-dried to estimate the final 286 litter mass. The remaining leaf material was coarsely crushed and an aliquot (mean $=21.60$ 287 $\mathrm{mg} \pm 0.13 \mathrm{SE}$ ) was used to determine the ergosterol content in the leaf litter as a surrogate of fungal biomass ( $\mathrm{mg} \mathrm{g}^{-1}$ of litter). Ergosterol was determined using high-performance lipid 
289

290

291

292

293

294

295

296

297

298

299

300

301

302

303

304

305

306

307

308

309

310

311

312

313

chromatography and was converted into dry mass using a factor of 182 (Gessner and Chauvet

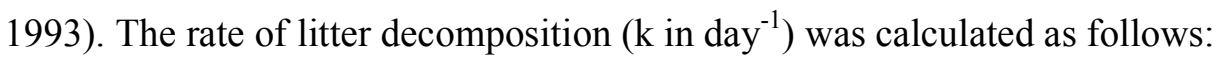

$$
\mathrm{k}=-\ln \left(\mathrm{M}_{\mathrm{f}} / \mathrm{M}_{\mathrm{i}}\right) / \mathrm{t}
$$

where $M_{f}$ and $M_{i}$ are the final and initial freeze-dried mass of leaf litter remaining in the microcosm, respectively, and $\mathrm{t}$ is the duration of the microcosm experiment (54 days).

\section{Statistical analyses}

\section{Intraspecific trophic variability in wild populations}

To ensure long-term comparisons of diet variability between and within populations, $\delta^{13} \mathrm{C}$ and $\delta^{15} \mathrm{~N}$ values of each L. gibbosus were used to calculate a measure of trophic position (TP) and the corrected carbon isotope ratio $\left(\delta^{13} \mathrm{C}_{\text {cor }}\right)$ adjusted for between-population variation in stable isotope baselines following Post (2002) (Appendix A):

$$
\begin{gathered}
\mathrm{TP}=\lambda_{\text {base }}+\left(\delta^{15} \mathrm{~N}_{\text {ind }}-\left[\delta^{15} \mathrm{~N}_{\text {lit }} \times \delta^{13} \mathrm{C}_{\mathrm{cor}}+\delta^{15} \mathrm{~N}_{\text {pel }} \times\left(1-\delta^{13} \mathrm{C}_{\text {cor }}\right)\right]\right) / \Delta_{\mathrm{N}} \\
\delta^{13} \mathrm{C}_{\text {cor }}=\left(\delta^{13} \mathrm{C}_{\text {ind }}-\delta^{13} \mathrm{C}_{\mathrm{pel}}\right) /\left(\delta^{13} \mathrm{C}_{\text {lit }}-\delta^{13} \mathrm{C}_{\mathrm{pel}}\right)
\end{gathered}
$$

where $\lambda_{\text {base }}$ is the trophic position of the littoral and pelagic baseline $\left(\lambda_{\text {base }}=2\right), \delta^{15} \mathrm{~N}_{\text {ind }}$ is the stable isotope value of the L. gibbosus, $\delta^{15} \mathrm{X}_{\text {lit }}$ and $\delta^{15} \mathrm{X}_{\mathrm{pel}}$ are the stable isotope values of the littoral and pelagic baselines and $\Delta_{\mathrm{N}}$ is the trophic enrichment factor obtained from previous studies $\left(\Delta_{\mathrm{N}}=3.4\right.$; Post 2002). Using these baseline-corrected isotope values that allow comparison between populations, the size of the isotopic niche of each population was calculated using Bayesian standard ellipse area (SEA, 10000 simulations) using Stable Isotope Bayesian Ellipse in R (SIBER; Jackson et al. 2011) from the SIAR package (Parnell et al. 2010). This ellipse-based metric focuses on the core area of the isotopic niche and low values (i.e. low stable isotope area) indicate small isotopic niches. In addition, KruskallWallis test was used to test for significant differences in trophic position between wild populations of L. gibbosus. 
Based on SCA, PS $\mathrm{i}_{\mathrm{i}}$ was calculated (Appendix A) and the overall degree of individual specialization (IS) in each population was then determined as the average $\mathrm{PS}_{\mathrm{i}}$ of all individuals (Bolnick et al. 2002). For the sake of clarity, the index V $=1$ - IS was used in the present study, with values closer to 1 indicating a high level of trophic specialization in the population. Significant differences in the level of specialization between wild populations were tested using Kruskall-Wallis test. Generalized linear mixed-effects model (package lme4 v.1.1.10; Bates et al. 2015), with site as a random factor, tested the effect of body size on diet variation, with $\mathrm{PS}_{\mathrm{i}}$ and FL used as independent and dependent variables respectively. Since $\mathrm{PS}_{\mathrm{i}}$ varied between 0 and 1 , the model specified a binomial family with a logistic link function.

\section{Effects of intraspecific trophic variability on nutrient recycling rates}

Two-way nested analysis of variance (ANOVA) tested the response of fish (growth and excretion rates) to the experimental treatments. In the experimental design, diet composition (defined as the number and types of food items: each item singly: $[\mathrm{R}]-[\mathrm{C}]-[\mathrm{F}]$, each item pair: $[\mathrm{RC}]-[\mathrm{RF}]-[\mathrm{CF}]$, and the three-items combination: [RCF]; Fig. 1) was nested in trophic specialization (the number of food items supplied to fish: 1-2-3; Fig. 1). The nested design was analyzed using the linear model:

$$
\mathrm{Y}_{\mathrm{ijk}}=\mu+\alpha_{\mathrm{i}}+\beta_{\mathrm{j}(\mathrm{i})}+\varepsilon_{\mathrm{ijk}}
$$

where $Y_{i j k}$ is the rate of growth or excretion of the $\mathrm{k}^{\text {th }}$ fish fed with the $\mathrm{j}^{\text {th }}$ type of diet within the $i^{\text {th }}$ level of specialization, $\alpha_{i}$ is the effect of $i^{\text {th }}$ level of specialization, $\beta_{j(i)}$ is the effect of the

$335 \mathrm{j}^{\text {th }}$ diet nested in the $\mathrm{i}^{\text {th }}$ level of specialization, and $\mu$ and $\varepsilon_{\mathrm{ijk}}$ are the intercept and residual error 336 of the model respectively. Two error terms are required for significance testing: specialization was tested against diet composition and diet composition against residual error (Quinn and 
significantly differed. Because excretion rates are a function of size, allometry was integrated into the analyses of nutrient excretion rates by dividing per capita excretion rates by $\mathrm{W}_{\mathrm{f}}$ raised to the $3 / 4$ power (mass-normalized per capita excretion rates; Torres and Vanni 2007). Nonadditive effects of diet mixing on response variables were evaluated through a comparison of the observed versus expected values using one-sample paired t-test. Specifically, for each mixed-diet treatment ( 3 intermediates and 1 generalist), the expected value was calculated as the mean value of specialist fish fed with either one of the food items. Given the multiplicity of comparisons involved, the false discovery rate (FDR; Benjamini and Hochberg 1995) procedure was applied to correct for alpha inflation using the p.adjust function (base-package v.3.1.2; R Development Core Team 2013). The significant results after the FDR procedure are reported.

\section{Effects of consumer-mediated nutrient recycling on ecosystem functioning}

The general effects of the presence of excretory products on ecosystem processes were evaluated by comparing nutrient-less (i.e. control) with all treatments that contained fish excretory products using t-tests. Linear models were used to examine effects of amounts of excretory products (per capita $\mathrm{N}$ and $\mathrm{P}$ excretion rates) on ecosystem processes measured in the microcosms (i.e. particulate nutrient content, gross primary productivity, community respiration, algal standing biomass, fungal biomass on leaves and litter decomposition rates). To assess the mass dependence of nutrient excretion effects on ecosystem processes, linear models were also performed with mass-normalized per capita excretion rates and ecosystem processes as independent and dependent variables, respectively. Linear models were built with a block effect as covariate to control for potential variation in the experimental set-up. The assumption of homoscedasticity and the normality of the residuals for linear models and nested ANOVA were checked graphically using Tukey Ascombe and Q-Q plots, respectively. 
364 Prior to all statistical analyses, nutrient excretion rates and fungal biomass were $\log _{10}$ 365 transformed and growth rate was square-root transformed. Highly influential data points were 366 identified by the Cook's distance $\left(D_{i}\right)$ plot and values were considered as critical for $D_{i}>4 / N$, 367 where $\mathrm{N}$ is the number of observations (Bollen and Jackman 1990). Critical values were 368 removed from the dataset prior the model was refitted. All statistical analyses were performed using R v.3.1.2 (R Development Core Team 2013).

\section{RESULTS}

372

Intraspecific trophic variability in wild populations

374 Isotopic niche size $\left(\mathrm{SEA}_{\mathrm{b}}\right.$, mean $\left.=0.33 \pm 0.02 \mathrm{SE}\right)$ could increase up to two times between populations, ranging from 0.25 up to 0.48 (Table 1; Appendix A, Fig. A1), indicating that variations in isotopic niche across populations were apparent when the temporally integrated

377 SIA was used. In addition, trophic position significantly differed between populations 378 (Kruskal-Wallis, $\mathrm{H}=127.31, P<0.001$ ). Within-populations, SIA also indicated relatively 379 high variability in trophic position, with the range of trophic position extending over more than one trophic level in several cases (mean $\mathrm{TP}=3.37 \pm 0.06 \mathrm{SE}$, mean within-population range $=1.32 \pm 0.05 \mathrm{SE}$; Table 1; Appendix A, Fig. A1). These results suggested that individuals of L. gibbosus integrate across a wide range of resources with different trophic positions (i.e. from primary producer to secondary consumer), as individuals feeding exclusively on invertebrates would have a trophic position of 3 .

SCA revealed that the level of trophic specialization (V ranging from 0.17 to 0.64 ; mean $=0.38 \pm 0.05 \mathrm{SE}$ ) was significantly different between populations (Kruskal-Wallis, $\mathrm{H}=$ 
388

389

390

391

392

393

(Table 1; Appendix A, Fig. A2) and increased nine-fold on average among individuals (Table 1). The relationship between FL and $\mathrm{PS}_{\mathrm{i}}$ was not significant $(\mathrm{GLMM}, \mathrm{z}=0.55, P=0.581)$.

\section{Effects of intraspecific trophic variability on nutrient recycling rates}

Laboratory experiment revealed that individual growth rate did not vary significantly with the degree of specialization but was significantly affected by diet composition (nested ANOVAs, $P=0.627$ and $P<0.001$, respectively; Table 2). Specialists feeding on fish meat exhibited higher individual growth rates than individuals feeding on rice (Fig. 2A) and values obtained from mixed diet were not significantly different from predicted values based on mixing of single values $(P>0.227)$.

At the end of the experiment, the excretion rates of the individual L. gibbosus displayed a wide range of variation among individuals, ranging from 4.12 to $22.61 \mu \mathrm{mol} \mathrm{N}$ ind. $^{-1} \mathrm{~h}^{-1}$ and from 0.04 to $0.29 \mu \mathrm{mol} \mathrm{P}$ ind. $^{-1} \mathrm{~h}^{-1}$, but mass-normalized excretion rates did not significantly differ between the degrees of diet specialization (nested ANOVAs, $P=0.897$ and $P=0.164$, respectively; Table 2 ). Diet composition significantly affected massnormalized $\mathrm{N}$ excretion rate (nested ANOVA, $P<0.001$; Table 2, Fig. 2B) whereas it did not significantly affect mass-normalized $\mathrm{P}$ excretion rate (nested ANOVA, $P=0.072$; Table 2, Fig. 2C). Mass-normalized $\mathrm{N}$ excretion rate was significantly different for the three specialist treatments, with the highest and lowest excretion rates for fish specialized on fish meat (mean $=19.11 \mu \mathrm{mol} \mathrm{N}$ ind. $.^{-1} \mathrm{~h}^{-1} \pm 1.11 \mathrm{SE}$ ) and rice (mean $=5.94 \mu \mathrm{mol} \mathrm{N}$ ind. $\left..^{-1} \mathrm{~h}^{-1} \pm 0.47 \mathrm{SE}\right)$, respectively (Fig. 2B). In general, these results suggested that the presence of fish meat within a diet also containing rice (i.e. $[\mathrm{RF}]$ and $[\mathrm{RCF}]$ ) increased mass-normalized $\mathrm{N}$ excretion rate when compared to specialists feeding on rice (Fig. 2B). In parallel, intermediate individuals feeding on rice and chironomids excreted $\mathrm{N}$ nutrients at similar rates to specialists feeding on 
412 rice (Fig. 2B). For both $\mathrm{N}$ and $\mathrm{P}$ mass-normalized excretion rates, additive effects were 413 observed for all mixed-diet treatment $(P>0.059)$.

414

\section{Effects of consumer-mediated nutrient recycling on ecosystem functioning}

416

417

418

Particulate $\mathrm{N}$ and $\mathrm{P}$ contents, gross primary production (GPP), community respiration (CR), and algal standing biomass (chlorophyll-a) were higher in microcosms supplied with fish excretory products than in control microcosms (t-tests, $P<0.05)$. Linear models showed that particulate $\mathrm{N}$ content, GPP and CR increased significantly with $\mathrm{N}$ excretion rate and that particulate $\mathrm{P}$ content and algal standing biomass increased significantly with $\mathrm{P}$ excretion rate (Table 3, Fig. 3). In contrast, whole-system metabolism did not change with $\mathrm{P}$ excretion rate (linear models, GPP: $\mathrm{F}=2.25, P=0.142$ and $\mathrm{CR}: \mathrm{F}=1.83, P=0.184$; Table 3, Fig. $3 \mathrm{~B}$ and 3D) and differences in algal standing biomass among microcosms were inconsistent with intraspecific variation in $\mathrm{N}$ excretion rate (linear model, $\mathrm{F}=0.12, P=0.732$; Table 3, Fig. 3E). No difference was detected for the biomass of leaf-associated fungi and litter decomposition rate between treatment and control microcosms (t-tests, $P=0.656$ and $P=$ 0.672, respectively; Fig. $3 \mathrm{~K}$ and $3 \mathrm{~L}$ ). Intraspecific variation in nutrient excretion rates did not explain differences in these ecosystem properties among microcosms that were supplied with fish excretory products (linear models, $P>0.367$; Table 3, Fig. 3G to 3J). Except for algal standing biomass (linear model, $\mathrm{F}=6.08, P=0.018$; Table 3), effects of $\mathrm{N}$ and $\mathrm{P}$ excretion rates on ecosystem properties were not statistically significant with mass-normalized excretion rates (linear models, $P>0.071$; Table 3 ), indicating that consumer-mediated effects on ecosystem processes were primarily driven by the effects of diet treatment on individual body mass through differences in growth rate.

\section{DISCUSSION}


438 The widespread occurrence of diet variability within populations is now recognized, although

439 its incidence and implications at the higher levels of biological organization remain poorly 440 understood (Bolnick et al. 2003, Araújo et al. 2011). Here, we observed that intraspecific 441 trophic variability occurred between and within wild populations of L. gibbosus. This was 442 partly due to high variability in both the degree of individual specialization and their trophic 443 position quantified using SCA and SIA. Variability in trophic position also suggested that 444 individuals consumed a range of plant and animal resources. The experimental approaches 445 then indicated that the rate of nutrient excretion was influenced by diet composition but did not change with the degree of specialization. Specifically, $\mathrm{N}$ excretion rate increased with diet 447 quality but $\mathrm{P}$ excretion rate did not change with diet composition. Finally, we found that increased nutrient excretion rates potentially enhanced integrative ecosystem processes through biomass-dependent effects.

Generalist populations with wide trophic niches are composed of more heterogeneous individuals using only a subset of the available prey (Bolnick et al. 2003). Here, we found that trophic specialization differed widely among coexisting individuals of $L$. gibbosus and such trophic variability was consistently detected within the eleven wild populations surveyed. In addition, omnivorous L. gibbosus individuals did not occupy the same trophic position, as evidenced by stable isotope analyses that reflect dietary information over several months (Layman et al. 2012). Clearly, individuals within populations differed in respect of the relative contribution of plant- versus animal-derived resources to diet, as supported by the 458 wide range of observed trophic position values. Plant material was commonly found in the stomach content of L. gibbosus in the present and previous studies (García-Berthou and Moreno-Amich 2000, Rezsu and Specziar 2006) and may be ingested while fish foraged on benthic prey embedded within sediments or macrophytes. While SCA suggested that $L$. 
462 gibbosus relied exclusively on invertebrate prey as animal food source, we cannot rule out 463 that some individuals displaying a high trophic position also consumed fish-derived prey such 464 as eggs and larvae (García-Berthou and Moreno-Amich 2000). For instance, in the present study, fish were sampled in late summer, i.e. at a time when fish eggs and larvae had become scarce since all co-occurring species have already spawned, which likely explained the absence of fish-derived prey in the stomach contents. Indeed, SCA provide only a snapshot of individuals' diets, unless repeated non-lethal stomach flushing are performed from the same individuals (Araújo et al. 2011). Nevertheless, SCA provided dietary information at the taxonomic level, with these data used to calculate trophic specialization based on count data. Since plant debris could not be quantified in the same way as animal prey, however, they were excluded from SCA and could not be including in the quantification of trophic specialization, which represents a limitation of this approach when using omnivorous model species. In contrast, SIA provides temporally-integrative information about individual diet, but precise quantification of the trophic niche can be difficult, particularly if putative resources are taxonomically distinct but isotopically similar. Therefore, the combined use of SIA and SCA is an appropriate way to counterbalance the limitations of each method to investigate the trophic ecology of omnivores. Variation in trophic enrichment factor can also be a source of uncertainty when quantifying the trophic position of wild organisms (Vander Zanden and Rasmussen 2001, Busst et al. 2015). Indeed, in omnivorous species, high variations in trophic position within and between wild populations. 
487

488

489

490

491

492

493

494

495

496

497

498

499

500

501

502

503

504

505

506

507

508

509

510

511

could provide fitness benefits (DeMott 1998). Our laboratory experiment did not support this hypothesis, as diet mixing did not increase individual growth. By contrast, growth rates were higher for individuals feeding on the single best-quality food item, whereas specialization on poorer-quality diet might induce low or negative growth rate (Lefcheck et al. 2013). These findings thus indicate that diet specialization toward high quality food may confer fitness advantages in generalist populations. However, in natural situations, consumers specializing on high food quality may expend more energy to capture their prey. For instance, predation on fish eggs can induce fighting costs and reciprocal predation, particularly in nest-guarding species (Baldridge and Lodge 2013). In parallel, species providing parental care, such as $L$. gibbosus, can also display cannibalism, particularly when guarding is costly (Manica 2002). Thus, specializing on high quality food may induce contradictory effects in fish in natural environments, although this requires further investigations.

Nutrient cycling measured as per capita excretion rates was highly variable among individuals (ranging from to 4.12 to $22.61 \mu \mathrm{mol} \mathrm{N}$ ind. ${ }^{-1} \mathrm{~h}^{-1}$ and from 0.04 to $0.29 \mu \mathrm{mol} \mathrm{P}$ ind. ${ }^{-1} \mathrm{~h}^{-1}$, respectively). These values were within the range reported by Villéger et al. (2012) for wild populations of freshwater fish species (ranging from 0.20 to $518 \mu \mathrm{mol} \mathrm{N}$ ind.-1 $\mathrm{h}^{-1}$ and from 0.03 to $29.34 \mu \mathrm{mol} \mathrm{P}$ ind.$^{-1} \mathrm{~h}^{-1}$ ). They were, however, slightly lower than the values observed for L. gibbosus (ranging from 13.46 to $26.12 \mu \mathrm{mol} \mathrm{N}$ ind..$^{-1} \mathrm{~h}^{-1}$ and from 0.13 to 1.74 $\mu \mathrm{mol} \mathrm{P}$ ind. $^{-1} \mathrm{~h}^{-1}$; Villéger et al. 2012). Although the effects of diet composition on consumer excretion rates can be difficult to predict (but see Moody et al. 2015), our findings revealed that individuals feeding at higher trophic position (i.e. those with an animal-based diet) excreted $\mathrm{N}$ at higher rates (Bassar et al. 2010). This is probably because animal items used in this study were nutrient-rich compared to rice and, correspondingly, consumers would release these nutrients at higher rates (Sterner and Elser 2002). Surprisingly, and contrary to findings reported in literature (Moody et al. 2015), we did not detect significant changes in P excretion 
512 rate in relation to intraspecific trophic variability. Fish require large amount of $\mathrm{P}$ that is

513 allocated to the formation of bones and scales, and to somatic growth (Pilati and Vanni 2007,

514 McIntyre and Flecker 2010). The diet items used in the present study were relatively low in P

515 (from 0.2 to $0.9 \%$ dry mass; Fig. 1) and this could explain the high level of P retention by

516 fish. For instance, the mean C:P ratios of diet items used in the experiment were higher (mean

$517=311.8 \pm 221.8 \mathrm{SD}$ ) than the mean threshold elemental ratio of carbon and phosphorus (i.e.

518 the nutrient ratio of an organism's diet where growth limitation of this organism switches from

519 one element to another; Sterner and Elser 2002) of nine freshwater fish species reported in the

520 literature $($ mean $=135.4 \pm 44.4 \mathrm{SD}$; Frost et al. 2006). This indicates that fast growth $L$.

521 gibbosus species (Copp and Fox 2007) was probably P-limited in our experiment, suggesting

522 that consumers with an $\mathrm{r}$ - or k-strategy would potentially have different role in nutrient

523 recycling.

524 Some of the integrative ecosystem processes measured during the present study 525 differed substantially among microcosms (i.e. gross primary productivity and community 526 respiration) and a significant fraction of this variability was driven by intraspecific variation 527 in the rate of nitrogen excreted by fish. Because we also demonstrated that diet composition 528 determined nitrogen excretion rate, it indicated that intraspecific trophic variability can alter 529 ecosystem functioning through consumer-mediated nutrient recycling (Bassar et al. 2010, 530 Taylor et al. 2015). Based on our findings, specialization toward resources with higher trophic 531 level should exacerbate the effects of individual fish excretion on ecosystem functioning. 532 Previous studies have demonstrated that increased nutrient quantity through loading can shape 533 consumer-mediated nutrient recycling, probably through changes in population biomass and/ 534 or community structure (Vanni et al. 2005, Wilson and Xenopoulos 2011). Here, we found 535 that the biomass dependence of fish excretion can also occur within the same cohort and 536 mediate the effects of consumers on ecosystem functioning. This highlights the importance of 
537 integrating body size variation in assessments of the effects of intraspecific variability on 538 ecosystem functioning (Rudolf and Rasmussen 2013). In addition, since human activities can 539 affect body size distribution in wild population (e.g. Evangelista et al. 2015), it would be of 540 interest to assess how they affect the relative importance of consumer-driven nutrient 541 recycling along a gradient of perturbation, such as anthropogenic eutrophication.

542 The amount of $\mathrm{N}$ and $\mathrm{P}$ associated with fine particulate organic matter increased with 543 the inputs of fish excretory products, but also as a result of microbial immobilization of 544 dissolved inorganic nutrients. Primary producers and decomposers rely on inorganic nutrients 545 for growth and metabolism (Daufresne and Loreau 2001). In our experiment, neither 546 decomposition rate of coarse particulate organic matter nor fungal biomass were modified by 547 the addition of excretory products, suggesting that litter-associated decomposers did not use 548 fish-derived nutrients. Therefore, and contrary to our prediction, producers may have 549 contributed substantially to nutrient immobilization in microcosms as evidenced by the 550 positive response of GPP and algal biomass to fish excretory products. Finally, the 551 asymmetric responses between autotroph and heterotroph organisms observed here 552 highlighted the complexity of ecosystem processes responses to nutrient loading. Although 553 these results are not trivial, we argue that future investigations are needed in less contrived 554 experimental environments. This would help to fully encompass other additional effects that 555 might modulate and interact with the relationship between nutrient recycling and ecosystem 556 processes (Knoll et al. 2009, Bassar et al. 2010, Taylor et al. 2012).

557 A large number of studies have demonstrated that changes in community structure or 558 population size can influence consumer-mediated nutrient recycling (Vanni et al. 2002, 559 McIntyre et al. 2007, Pilati and Vanni 2007, Villéger et al. 2012, Allgeier et al. 2016). In the 560 present study, we demonstrated that changes within populations can also induce variation in 561 consumer nutrient excretion rates and ecosystem processes, providing a deeper understanding 
562 of the indirect role of consumers in regulating ecosystem functioning. Together, these 563 findings highlight that the ecological effects induced by intraspecific variability in consumers 564 may be strong compared to those induced by interspecific variability (Palkovacs et al. 2015). 565 This would be particularly relevant in the current context of global changes in general and 566 biological invasions in particular, as they can alter the diversity patterns of consumers both at 567 the intraspecific and interspecific levels, affecting native organisms and recipient ecosystems 568 across levels of biological organization (Buoro et al. 2016). We also argue that future studies 569 would benefit to quantify the relative effects of top-down (direct and consumptive) and 570 bottom-up (indirect and nutrient-mediated) mechanisms in controlling the effects of 571 intraspecific variability on ecosystem functioning (Knoll et al. 2009, Taylor et al. 2015).

572

\section{ACKNOWLEDGEMENTS}

574 We are very grateful to the graviere team for their help during fish sampling and to N. 575 Charpin and T. Zhao for their help during experiment. D. Lambrigot and F. Julien are thanked 576 for their laboratory assistance. We also thank S. Villéger and two anonymous reviewers for 577 constructive comments on earlier version of the manuscript. Authorizations to perform this 578 study were provided by the "Arrêtés Préfectoraux - 31/07/2012 and 10/07/2013". This work

579 580

\section{REFERENCES}


587 Allgeier, J. E. et al. 2016. Fishing down nutrients on coral reefs. - Nature Communications 7:

$588 \quad 12461$.

589 Araújo, M. S. et al. 2011. The ecological causes of individual specialisation: The causes of $590 \quad$ individual specialisation. - Ecology Letters 14: 948-958.

591 Baldridge, A. K. and Lodge, D. M. 2013. Intraguild predation between spawning smallmouth 592 bass (Micropterus dolomieu) and nest-raiding crayfish (Orconectes rusticus) : implications 593 for bass nesting success. - Freshwater Biology 58: 2355-2365.

594 Bassar, R. D. et al. 2010. Local adaptation in Trinidadian guppies alters ecosystem processes. 595 - Proceedings of the National Academy of Sciences 107: 3616-3621.

596 Bates, D. D., et al. 2015. lme4: Linear mixed-effects models using Eigen and S4. R package 597 version 1.1-10. http://CRAN.R-project.org.

598 Benjamini, Y. and Hochberg, Y. 1995. Controlling the false discovery rate: a practical and 599 powerful approach to multiple testing. - Journal of the Royal Statistical Society Series B $600 \quad 57: 289-300$.

601 Bhagat, Y. et al. 2011. Trophic polymorphism in introduced pumpkinseed (Lepomis gibbosus) 602 inhabiting Iberian reservoirs. - Environmental Biology of Fishes 91: 203-217.

603 Bollen, K. A. and Jackman, R. W. 1990. Regression diagnostics: an expository treatment of 604 outliers and influential cases. In: Fox, J. and Long J. S. (ed), Modern methods of data 605 analysis. Sage Publication, Newbury Park, CA, pp257-291.

606 Bolnick, D. I. et al. 2002. Measuring individual-level resource specialization. - Ecology 83: $607 \quad 2936-2941$.

608 Bolnick, D. I. et al. 2003. The ecology of individuals: incidence and implications of individual 609 specialization. - The American Naturalist 161: 1-28. 
610 Buoro, M. et al. 2016. Global Salmonidae introductions reveal stronger ecological effects of 611 changing intraspecific compared to interspecific diversity. - Ecology Letters 19: 1363$612 \quad 1371$.

613 Busst, G. M. A. and Britton, J. R. 2016. High variability in stable isotope diet-tissue 614 discrimination factors of two omnivorous freshwater fishes in controlled ex situ conditions. 615 - The Journal of Experimental Biology 219: 1060-1068.

616 Busst, G. M. A. et al. 2015. Stable isotope signatures and trophic-step fractionation factors of 617 fish tissues collected as non-lethal surrogates of dorsal muscle: Non-lethal tissue surrogates 618 for fish isotope studies. - Rapid Communications in Mass Spectrometry 29: 1535-1544.

619 Capps, K. A. and Flecker, A. S. 2013. Invasive fishes generate biogeochemical hotspots in a 620 nutrient-limited system. - PLoS One 8: e54093.

621 Copp, G. H. and Fox, M. G. 2007. Growth and life history traits of introduced pumpkinseed 622 (Lepomis gibbosus) in Europe, and the relevance to its potential invasiveness. - In:

623 Biological invaders in inland waters: Profiles, distribution, and threats. Springer, pp. 289624306.

625 Currie, D. J. and Kalff J. 1984. A comparison of the abilities of freshwater algae and bacteria 626 to acquire and retain phosphorus. - Limnology and Oceanography 29: 298-310.

627 Daufresne, T. and Loreau, M. 2001. Ecological stoichiometry, primary producer-decomposer 628 interactions, and ecosystem persistence. - Ecology 82: 3069-3082.

629 DeMott, W. R. 1998. Utilization of a cyanobacterium and a phosphorus-deficient green alga 630 as complementary resources by daphnids. - Ecology 79: 2463-2481.

631 El-Sabaawi, R. W. et al. 2015a. Assessing the effects of guppy life history evolution on 632 nutrient recycling: from experiments to the field. - Freshwater Biology 26: 666-676.

633 El-Sabaawi, R. W. et al. 2015b. Intraspecific phenotypic differences in fish affect ecosystem 634 processes as much as bottom-up factors. - Oikos 24:1181-1191. 
635 Evangelista, C. et al. 2015. Impacts of invasive fish removal through angling on population 636 characteristics and juvenile growth rate. - Ecology and Evolution 5: 2193-2202.

637 Frost, P. C. et al. 2005. Are you what you eat? Physiological constraints on organismal 638 stoichiometry in an elementally imbalanced world. - Oikos 109: 18-28.

639 Frost, P. C. et al. 2006. Threshold elemental ratios of carbon and phosphorus in aquatic 640 consumers. - Ecology Letters 9: 774-779.

641 García-Berthou, E. and Moreno-Amich, R. 2000. Food of introduced pumpkinseed sunfish: 642 ontogenetic diet shift and seasonal variation. - Journal of Fish Biology 57: 29-40.

643 Gessner, M. O. and Chauvet, E. 1993. Ergosterol-to-biomass conversion factors for aquatic 644 hyphomycetes. - Applied and Environmental Microbiology 59: 502-507.

645 Glaholt, S. P. and Vanni, M. J. 2005. Ecological responses to simulated benthic-derived 646 nutrient subsidies mediated by omnivorous fish. - Freshwater Biology 50: 1864-1881.

647 Harmon, L. J. et al. 2009. Evolutionary diversification in stickleback affects ecosystem 648 functioning. - Nature 458: 1167-1170.

649 Jackson, A. L. et al. 2011. Comparing isotopic niche widths among and within communities: 650 SIBER - Stable Isotope Bayesian Ellipses in R: Bayesian isotopic niche metrics. - Journal 651 of Animal Ecology 80: 595-602.

652 Knoll, L. B. et al. 2009. Feedbacks of consumer nutrient recycling on producer biomass and 653 stoichiometry: separating direct and indirect effects. - Oikos 118: 1732-1742.

654 Layman, C. A. et al. 2012. Applying stable isotopes to examine food-web structure: an 655 overview of analytical tools. - Biological Reviews 87: 545-562.

656 Lefcheck, J. S. et al. 2013. Physiological effects of diet mixing on consumer fitness: a meta$657 \quad$ analysis. - Ecology 94: 565-572.

658 Manica, A. 2002. Filial cannibalism in teleost fish. - Biological Reviews of the Cambridge 659 Philosophical Society 77: 261-277. 
660 McCairns, R. J. S. and Fox, M. G. 2004. Habitat and home range fidelity in a trophically 661 dimorphic pumpkinseed sunfish (Lepomis gibbosus) population. - Oecologia 140: 271$662 \quad 279$.

663 McIntyre, P. B. and Flecker, A. S. 2010. Ecological stoichiometry as an integrative 664 framework in stream fish ecology. - In: Community ecology of stream fishes: concepts, 665 approaches, and techniques, pp 539-558. American Fisheries Society, Symposium 73: $666 \quad 539-558$.

667 McIntyre, P. B. et al. 2007. Fish extinctions alter nutrient recycling in tropical freshwaters. 668 Proceedings of the National Academy of Sciences 104: 4461-4466.

669 Moody, E. K. et al. 2015. Diet composition affects the rate and N:P ratio of fish excretion. $670 \quad$ Freshwater Biology 60:456-465.

671 Pace, M. L. et al. 1999. Trophic cascades revealed in diverse ecosystems. - Trends in ecology $672 \quad \&$ evolution 14: 483-488.

673 Palkovacs, E. P. et al. 2015. Ecological effects of intraspecific consumer biodiversity for 674 aquatic communities and ecosystems. - In: Aquatic Functional Biodiversity. Elsevier, pp. $675 \quad 37-51$.

676 Parnell, A. C. et al. 2010. Source partitioning using stable isotopes: coping with too much 677 variation. - PLoS ONE 5: e9672.

678 Pilati, A. and Vanni, M. J. 2007. Ontogeny, diet shifts, and nutrient stoichiometry in fish. 679 Oikos 116: 1663-1674.

680 Post, D. M. 2002. Using stable isotopes to estimate trophic position: models, methods, and 681 assumptions. - Ecology 83: 703-718.

682 Quevedo, M. et al. 2009. Intrapopulation niche partitioning in a generalist predator limits food 683 web connectivity. - Ecology 90: 2263-2274. 
684 Quinn, G. P. and Keough, M. J. 2002. Experimental design and data analysis for biologists. 685 Cambridge University Press, UK.

686 R Development Core Team. 2013. R: A Language and Environment for Statistical 687 Computing. R Foundation for Statistical Computing, Vienna, Austria.

688 Rezsu, E. and Specziar, A. 2006. Ontogenetic diet profiles and size-dependent diet 689 partitioning of ruffe Gymnocephalus cernuus, perch Perca fluviatilis and pumpkinseed 690 Lepomis gibbosus in Lake Balaton. - Ecology of Freshwater Fish 15: 339-349.

691 Rudolf, V. H. and Rasmussen, N. L. 2013. Ontogenetic functional diversity: Size structure of 692 a keystone predator drives functioning of a complex ecosystem. - Ecology 94: 1046-1056.

693 Small, G. E. et al. 2011. Role of the fish Astyanax aeneus (Characidae) as a keystone nutrient 694 recycler in low-nutrient Neotropical streams. - Ecology 92: 386-397.

695

696

697

698

699

700

701

702

703

704

705

706

707

708

Smith, T. B. and Skúlason, S. 1996. Evolutionary significance of resource polymorphisms in fishes, amphibians, and birds. Annual Review of Ecology and Systematics 27: 111-133.

Steinman, A. D. et al. 2006. Biomass and pigments of benthic algae. - In: Hauer, F. R. and Lamberti, G. A. (ed.), Methods in stream ecology. Elsevier, Burlington, Massachusetts, USA pp. 357-379.

Sterner, R. W. and Elser J. J. 2002. Ecological stoichiometry: the biology of elements from molecules to the biosphere. Princeton University Press, Princeton, New Jersey, USA.

Svanbäck, R. et al. 2015. Individuals in food webs: the relationships between trophic position, omnivory and among-individual diet variation. - Oecologia 178: 103-114.

Taylor, J.M. et. al. 2012. Fish-mediated nutrient cycling and benthic microbial processes: can consumers influence stream nutrient cycling at multiple spatial scales? - Freshwater Science 31: 928-944.

Taylor, J. M. et al. 2015. Top-down and bottom-up interactions in freshwater ecosystems: emerging complexities. In: Hanley, T. C. and La Pierre, K. J. (ed.), Trophic ecology: 
709 bottom-up and top-down interactions across aquatic and terrestrial systems. Cambridge $710 \quad$ University Press, pp. 55-87.

711 Torres, L. E. and Vanni M. J. 2007. Stoichiometry of nutrient excretion by fish: interspecific 712 variation in a hypereutrophic lake. - Oikos 116: 259-270.

713 Vander Zanden, M. J. and Rasmussen, J. B. 2001. Variation in $\delta^{15} \mathrm{~N}$ and $\delta^{13} \mathrm{C}$ trophic 714 fractionation: implications for aquatic food web studies. - Limnology and Oceanography 715 46: 2061-2066.

716 Vanni, M. J. et al. 2002. Stoichiometry of nutrient recycling by vertebrates in a tropical 717 stream: linking species identity and ecosystem processes. - Ecology Letters 5: 285-293.

718 Vanni, M. J. et al. 2005. Linking landscapes and food webs: effects of omnivorous fish and 719 watersheds on reservoir ecosystems. - BioScience 55: 155-167.

720 Villéger, S. et al. 2012. Intra- and interspecific differences in nutrient recycling by European 721 freshwater fish. - Freshwater Biology 57: 2330-2341.

722 Vrede, T. et al. 2011. Ecological stoichiometry of Eurasian perch - intraspecific variation due 723 to size, habitat and diet. - Oikos 120: 886-896.

724 Wilson, H. F. and Xenopoulos, M. A. 2011. Nutrient recycling by fish in streams along a 725 gradient of agricultural land use. - Global Change Biology 17: 130-139.

726 Zhao, T. et al. 2016. Environmental determinants of fish community structure in gravel pit 727 lakes. - Ecology of Freshwater Fish 25: 412-421. 
729 Table 1 Mean value $\left( \pm 95 \%\right.$ CI or \pm SE) and range of trophic niche $\left(\mathrm{SEA}_{\mathrm{b}}\right)$, trophic position $730(\mathrm{TP})$ and individual specialization $\left(\mathrm{PS}_{\mathrm{i}}\right)$ in each studied wild population $(\mathrm{n}=11)$. The

731

732

\begin{tabular}{|c|c|c|c|c|c|c|c|c|}
\hline & $\mathbf{S E A}_{b}$ & & & TP & & & $\overline{S_{i}}$ & \\
\hline Lake & Mean $( \pm 95 \% \mathrm{CI})$ & $\mathrm{n}^{7}$ & Mean $( \pm$ SE $)$ & Range & $\mathrm{n}^{5}$ & Mean $( \pm \mathrm{SE})$ & Range & $\mathrm{n}^{7}$ \\
\hline A & $0.27(0.18-0.37)$ & 28 & $3.10(0.02)$ & $2.82-3.43$ & 28 & $0.36(0.05) * * *$ & $0.09-0.62$ & 12 \\
\hline B & $0.38(0.24-0.52)$ & 28 & $3.13(0.04)$ & $2.85-3.72$ & 28 & $0.83(0.03) * *$ & $0.27-0.97$ & 26 \\
\hline $\mathrm{C}$ & $0.32(0.21-0.44)$ & 28 & $3.41(0.03)$ & $3.13-3.64$ & 28 & $0.77(0.03) * * *$ & $0.22-0.92$ & 26 \\
\hline $\mathrm{D}$ & $0.30(0.20-0.42)$ & 28 & $3.40(0.04)$ & $2.89-3.94$ & 28 & $0.59(0.04) * * *$ & $0.08-0.82$ & 25 \\
\hline $\mathrm{E}$ & $0.27(0.18-0.37)$ & 28 & $3.56(0.03)$ & $3.19-3.86$ & 28 & $0.73(0.04) * * *$ & $0.15-0.92$ & 28 \\
\hline $\mathrm{F}$ & $0.32(0.21-0.44)$ & 27 & $3.29(0.04)$ & $2.67-3.74$ & 27 & $0.67(0.04) * *$ & $0.07-0.85$ & 26 \\
\hline G & $0.40(0.26-0.55)$ & 28 & $3.65(0.06)$ & $2.74-4.56$ & 28 & $0.75(0.05) * * *$ & $0.05-0.95$ & 26 \\
\hline $\mathrm{H}$ & $0.35(0.23-0.48)$ & 28 & $3.61(0.06)$ & $3.16-4.34$ & 28 & $0.42(0.03) * * *$ & $0.05-0.72$ & 23 \\
\hline I & $0.48(0.31-0.67)$ & 28 & $3.21(0.07)$ & $2.37-3.64$ & 28 & $0.40(0.03) * * *$ & $0.10-0.77$ & 28 \\
\hline $\mathrm{J}$ & $0.32(0.20-0.45)$ & 24 & $3.35(0.04)$ & $3.01-3.63$ & 24 & $0.81(0.04) * * *$ & $0.08-0.94$ & 22 \\
\hline K & $0.25(0.17-0.35)$ & 28 & $3.36(0.02)$ & $3.13-3.52$ & 28 & $0.50(0.04) * * *$ & $0.08-0.78$ & 26 \\
\hline
\end{tabular}


746 Table 2 Results of the nested ANOVAs used to assess the effects of diet composition nested 747 under degree of specialization on growth $\left(\%\right.$ week $^{-1}$; square-root transformed $)$ and the mass748 normalized $\mathrm{N}$ and $\mathrm{P}$ per capita excretion rates ( $\mu \mathrm{mol} \mathrm{g} \mathrm{g}^{-3 / 4} \mathrm{~h}^{-1} ; \log _{10}$ transformed) of Lepomis 749 gibbosus. Significant $P$-values are in bold.

\begin{tabular}{lllllll}
\hline Response variables & Source & df & Mean squares & F & $\boldsymbol{P}$ & Eta-squared \\
\hline Growth rate & Degree of specialization & 2 & 0.476 & 0.34 & 0.627 & 0.13 \\
& Diet composition & 4 & 1.415 & 87.72 & $<\mathbf{0 . 0 0 1}$ & 0.78 \\
& Error & 38 & 0.016 & & & \\
N excretion rate & Degree of specialization & 2 & 0.011 & 0.07 & 0.897 & 0.03 \\
& Diet composition & 4 & 0.156 & 36.01 & $<\mathbf{0 . 0 0 1}$ & 0.76 \\
P excretion rate & Error & 41 & 0.004 & & & \\
& Degree of specialization & 2 & 0.064 & 1.66 & 0.164 & 0.14 \\
& Diet composition & 4 & 0.039 & 2.34 & 0.072 & 0.17 \\
& Error & 39 & 0.016 & & & \\
\hline
\end{tabular}

750

751

752

753

754

755

756

757

758

759

760

761

762

763

764

765 
766 Table 3 Results of the linear models assessing the relationships between $\mathrm{N}$ and $\mathrm{P}$ per capita

767 ( $\mu \mathrm{mol}$ ind.$^{-1} \mathrm{~h}^{-1} ; \log _{10}$ transformed) and mass-normalized per capita excretion rates $\left(\mu \mathrm{mol} \mathrm{g}^{-3 / 4}\right.$ $768 \mathrm{~h}^{-1} ; \log _{10}$ transformed) and ecosystem processes: nutrient particulate content ( $\left.\mu \mathrm{mol}\right)$, gross 769 primary productivity $\left(\mathrm{mg} \mathrm{O}_{2}\right)$, community respiration $\left(\mathrm{mg} \mathrm{O}_{2}\right)$, algal standing biomass $(\mu \mathrm{g})$, 770 fungal biomass $\left(\mathrm{mg} ; \log _{10}\right.$ transformed) and litter decomposition rate $\left(\right.$ day $\left.^{-1}\right)$. Significant $P$ 771 values are in bold. 


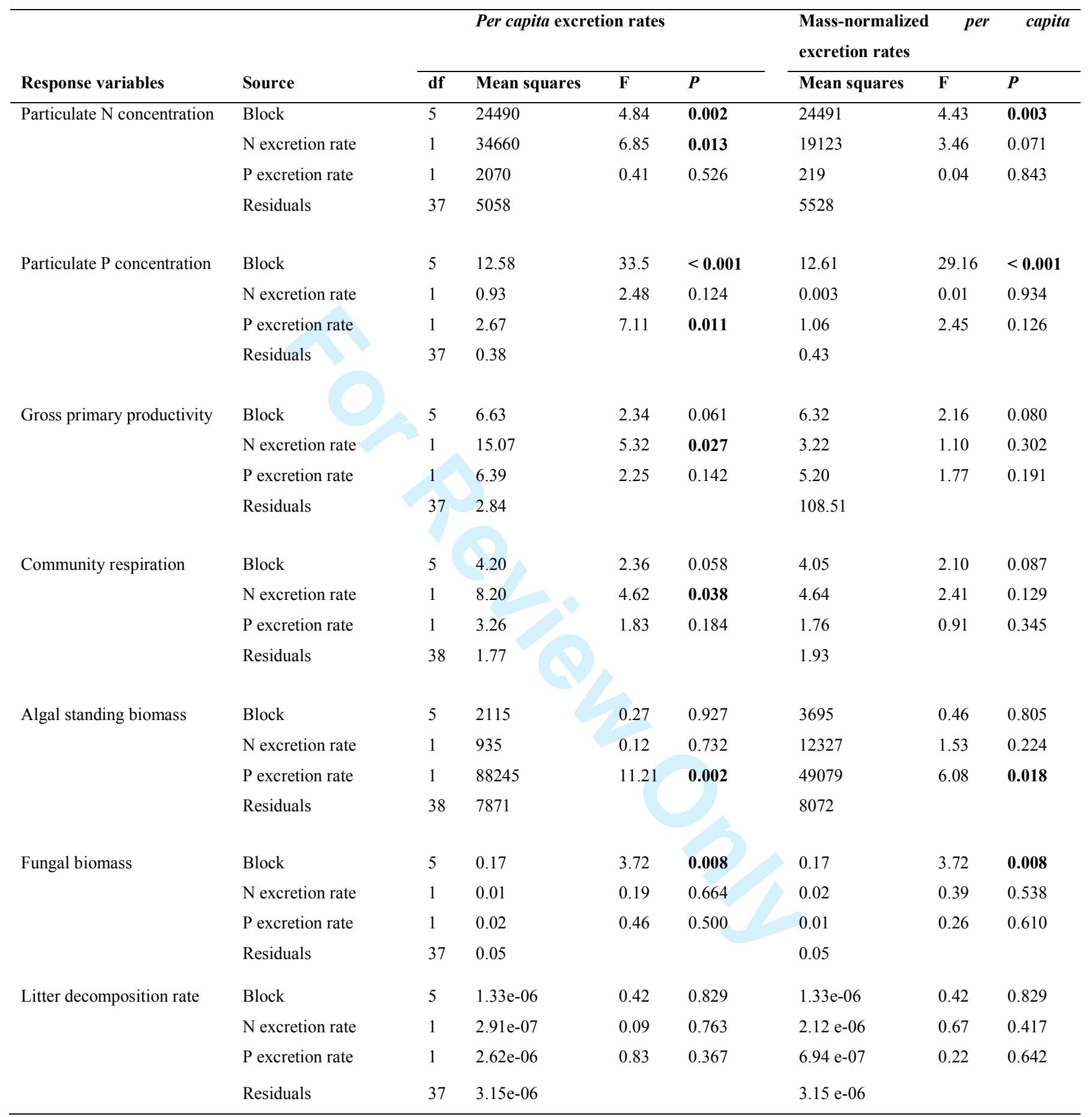

773

774

775

776 
777

778

779

780

781

782

783

784

785

786

787

788

789

790

791

792

793

794

795

796

797

798

799

800

801

\section{Figure legends}

Figure 1 Schematic representation of the experimental design used to test the indirect effects (i.e. through nutrient recycling) of inter-individual trophic variability on individuals and ecosystem functioning. Trophic variability was manipulated with diet elemental composition nested under degree of specialization. Replicated treatments were dispatched in 6 vertical shelving units (blocks). The degree of individual trophic specialization $\left(\mathrm{PS}_{\mathrm{i}}\right)$ was $0.33,0.66$ and 0.99 for specialist, intermediate and generalist treatments, respectively. Abbreviations: R: cooked rice; C: chironomid larvae; F: fish meat.

Figure 2 Effects of diet elemental composition treatment nested under degree of specialization treatment on mean $( \pm \mathrm{SE})(\mathrm{A})$ growth rate $\left(\% \mathrm{month}^{-1}\right)$ and $(\mathrm{B}) \mathrm{N}$ and $(\mathbf{C}) \mathrm{P}$ mass-normalized per capita excretion rates $\left(\mu \mathrm{mol} \mathrm{g}^{-3 / 4} \mathrm{~h}^{-1}\right)$. Colored dots represent rice specialists (yellow), chironomids specialists (blue), fish specialists (red), intermediates rice $\times$ chironomids $($ green), intermediates rice $\times$ fish (orange), intermediates chironomid $\times$ fish (purple) and generalists (dark green). Different letters indicate significant differences among these means (Tukey's HSD, $P<0.05$ ).

Figure 3 Relationship between N (left panels) and P (right panels) per capita excretion rates ( $\mu \mathrm{mol} \mathrm{\text {ind } ^ { - 1 }} \mathrm{h}^{-1} ; \log _{10}$ transformed) and (A-B) gross primary productivity $(\mathrm{n}=45),(\mathbf{C}-\mathbf{D})$ respiration $(\mathrm{n}=46),(\mathbf{E}-\mathbf{F})$ algal standing biomass $(\mu \mathrm{g} ; \mathrm{n}=46),(\mathbf{G}-\mathbf{H})$ fungal biomass $(\mathrm{mg} ; \mathrm{n}$ $=45)$ and $(\mathbf{I}-\mathbf{J})$ litter decomposition rate $\left(\right.$ day $\left.^{-1} ; \mathrm{n}=45\right)$. Regression lines are displayed using continuous black lines with equations above each panel when significant. The dotted lines represent the mean value of the control microcosms. 
Page 37 of 48

Oiks

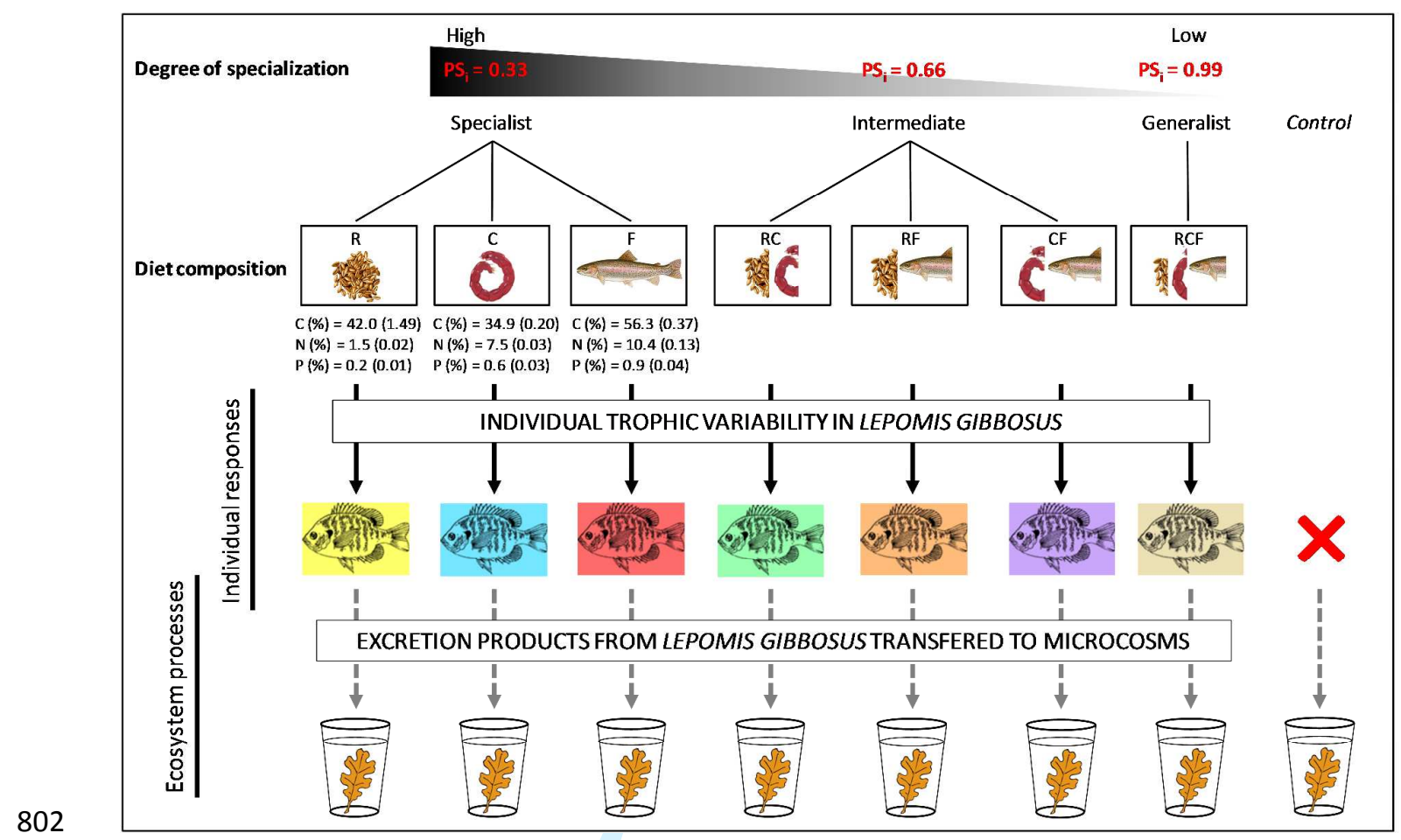

803

Figure 1

804

36 

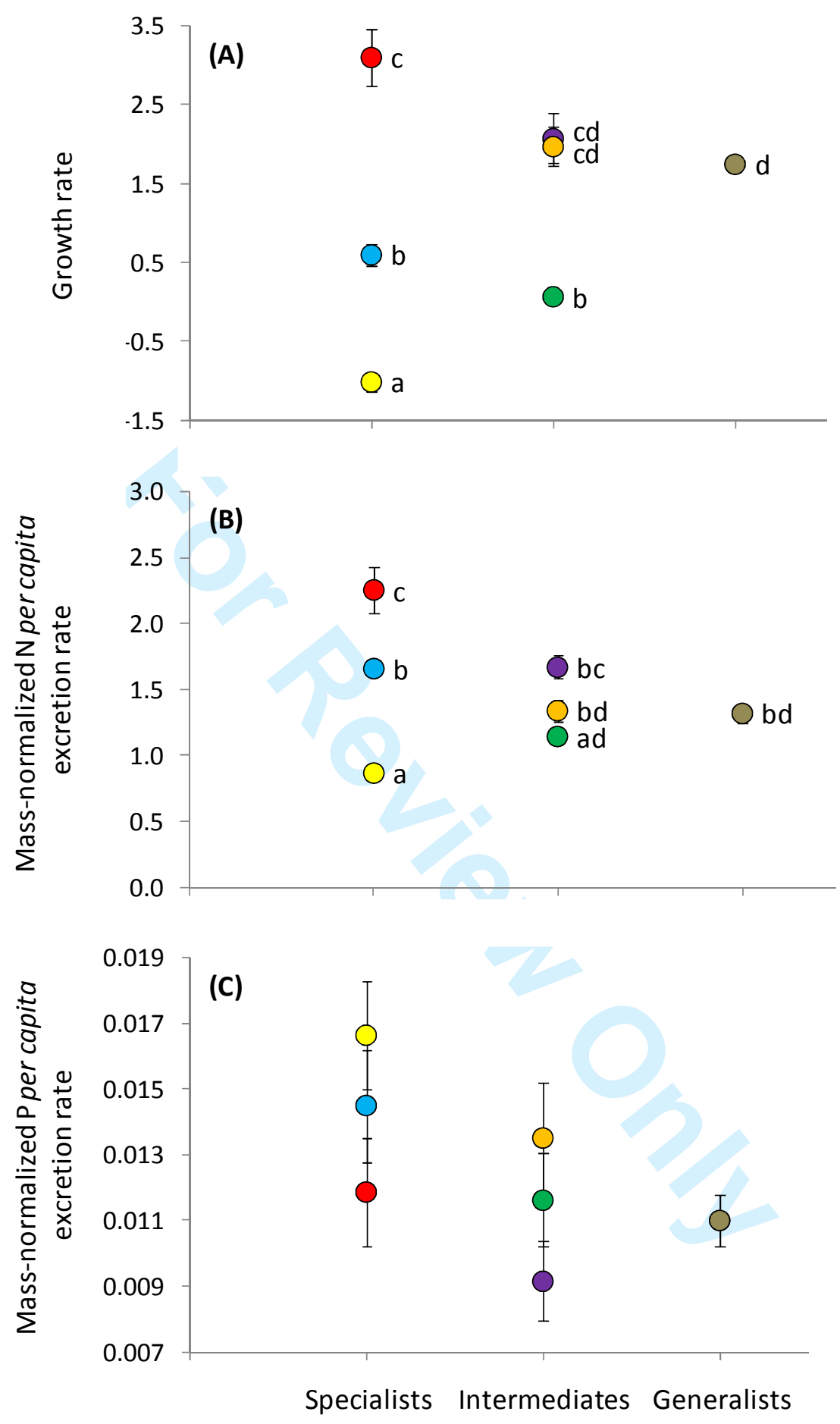

806

Figure 2

807

808

809 
(A) GPP $=16.3+3.4 \times \log _{10}\left(\mathrm{NH}_{4}{ }^{+}\right) ; \mathrm{R}^{2}=0.34$

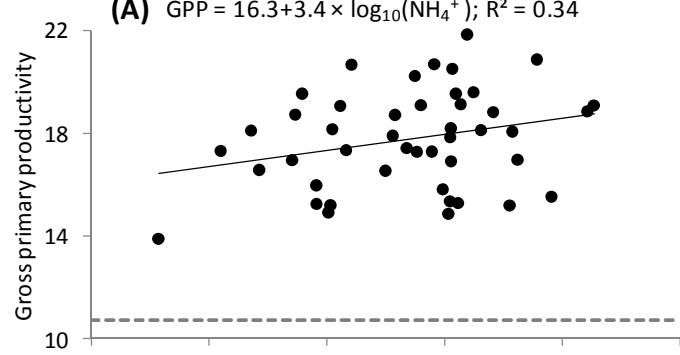

(C) $R=11.8+2.5 \times \log _{10}(\mathrm{SRP}) ; \mathrm{R}^{2}=0.32$

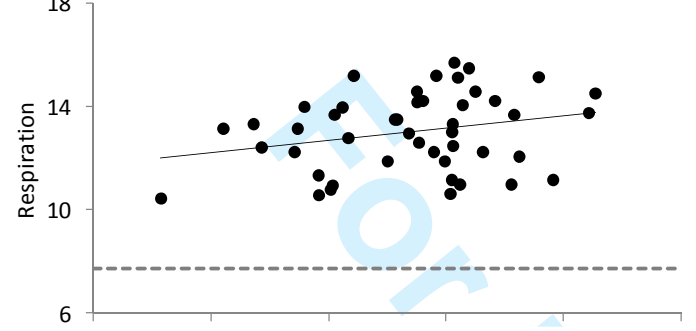

(E)

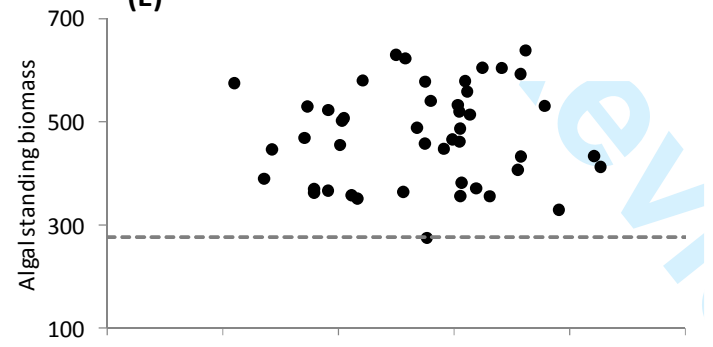

(G)

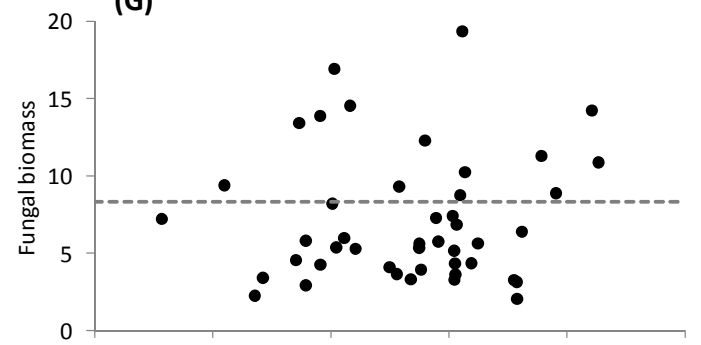

(I)

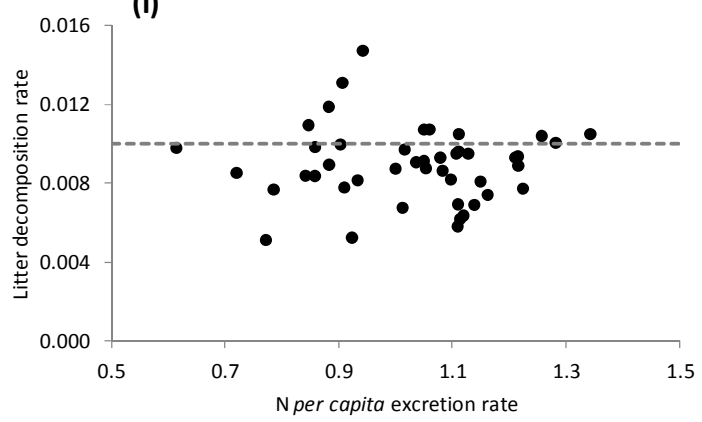

(B)

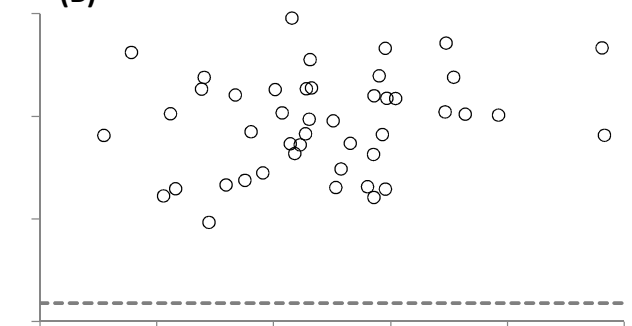

(D)

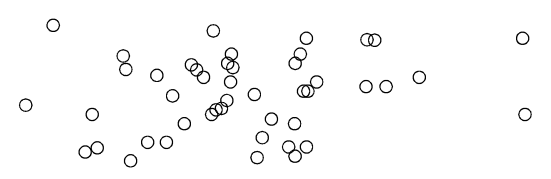

(F) Algal $=754.8+277.9 \times \log _{10}(S R P) ; R^{2}=0.25$

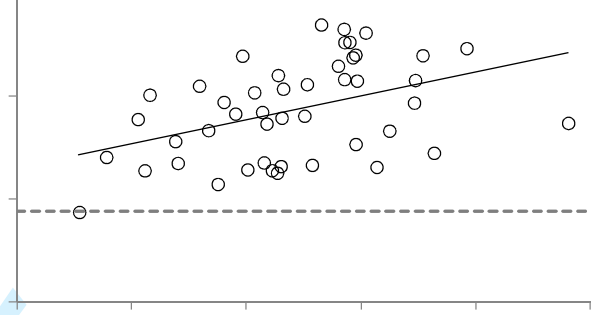

(H)

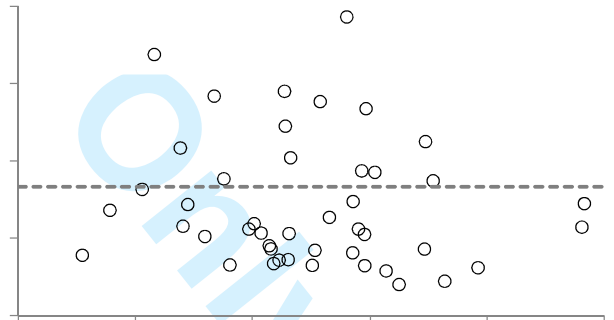

(J)

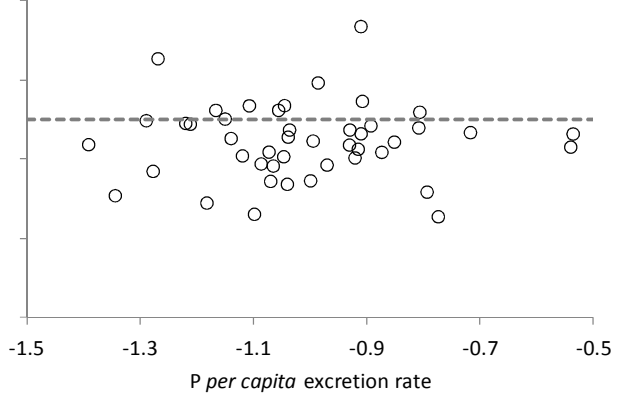


815

816

817 Resource composition mediates the effects of intraspecific variability in nutrient

818 recycling on ecosystem processes

819

820

821

C. Evangelista, A. Lecerf, J.R. Britton, J. Cucherousset

822

823

824

825

826

827

828

829

830

831

832

833

834

835

836

837

838

839

840

841

842

843 


\section{Evangelista, A. Lecerf, J.R. Britton, J. Cucherousset. Resource composition mediates}

Appendix A: Stomach content and stable isotope analyses.

850

\section{Stomach content analyses}

852

Stomach content analyses are traditional approaches used to examine the feeding ecology of consumers in wild populations (Svanbäck and Bolnick 2007, Robinson et al. 1993). In the present study, stomach contents of wild L. gibbosus were dissected under microscope and prey items were counted and identified to the lowest taxonomic level (mostly family level). A total of 70 prey taxa were found, including numerous invertebrate families and eggs. To assist analysis, within orders, several families were grouped into similar morphotype groups (aquatic larvae, emergent invertebrates or terrestrial invertebrates) and ultimately provided 29 prey categories for SCA. Importantly, although present in stomach content, plant detritus could not be counted and were thus excluded from subsequent analyses.

Indices were developed to calculate individual specialization using the population's total diet to define resource availability, involving that individuals are compared to their population niche rather than to the food availability (Bolnick et al. 2002). In the present study, we used the proportional similarity index (PS) to measure diet overlap between individual i and its population following Bolnick et al. (2002):

"where $\mathrm{p}_{\mathrm{ij}}$ is the proportion of the $j$ th resource category in individual $i$ 's diet, $\mathrm{q}_{\mathrm{ij}}$ is the proportion of the $j$ th resource category in the population's niche and is calculated as:

$$
\mathrm{q}_{\mathrm{ij}}=\frac{\sum_{i} n_{i j}}{\sum_{i} \sum_{j} n_{i j}}
$$

where $\mathrm{n}_{\mathrm{ij}}$ represent the number of diet items in individual $i$ 's diet that fall in category $j$. For individuals that specialize on a single diet item $j, \mathrm{PS}_{\mathrm{i}}$ takes on the value $\mathrm{q}_{\mathrm{j}}$. For individuals that

872 consume resources in direct proportion to the population as a whole, PS $_{\mathrm{i}}$ will equal 1." 873 (Bolnick et al. 2002). $\mathrm{PS}_{\mathrm{i}}$ were calculated using the package RInSp (Zaccarelli et al. 2013). 874 For each L. gibbosus, the count of prey items was converted to proportions and averaged 
875 across all individuals for each resource (Bolnick et al. 2002). The significance of $\mathrm{PS}_{\mathrm{i}}$ was 876 evaluated using resampling methods based on Monte Carlo procedures (using 10000 877 replicates). The null hypothesis was that any observed diet variation arose from individuals sampling stochastically from a shared distribution (Araújo et al. 2011).

\section{Stable isotope analyses}

881

Stable isotope analyses are useful tools to investigate the trophic ecology of consumers in wild populations with the particularity to integrate dietary information through time (Layman et al. 2012). For instance, stable isotope values in fish muscle samples provide dietary information over 2 to 8 weeks (Boecklen et al. 2011). The stable isotope ratio of carbon and nitrogen (noted $\delta^{13} \mathrm{C}$ and $\delta^{15} \mathrm{~N}$, respectively) are commonly used to diet reconstruction due to their abilities to discriminate between different origin of resources (e.g. pelagic versus littoral), and differential trophic position (Post 2002). gibbosus selected in each population. In addition, the stable isotope values of putative prey resources were analyzed in each population during fish sampling (mid-September to midOctober 2012) to inform on the diet of Lepomis gibbosus during the period of their maximal growth rate (summer period). Specifically, littoral and pelagic prey resources were collected in different locations when available to account for potential spatial variability within each lake. The $\delta^{13} \mathrm{C}$ and $\delta^{15} \mathrm{~N}$ values of littoral prey consisted of mean values of the most common invertebrates sampled in the littoral habitat with a pond net (Chironomidae, Ephemeroptera, Gastropoda, Assellidae and Oligochaeta; $n=1$ to 4 samples per lake; $n=1$ to 6 individuals per sample). Isotope analyses for Gastropoda were performed on the soft muscle tissue. Stable isotope values of pelagic prey were obtained from zooplankton and Chironomidae samples (n

$900=3-4$ samples per lake; $\mathrm{n}=2-3$ chironomids per sample) collected in the pelagic habitat 901 with a 100- $\mu \mathrm{m}$ mesh net and an Ekman dredge, respectively.

902 Prior to all analyses, stable isotope samples were oven dried for $48 \mathrm{~h}$ at $60{ }^{\circ} \mathrm{C}$, ground 903 in a fine powder using a mortar and pestle and then analyzed at the Cornell Isotope 904 Laboratory (Ithaca, New York, USA). The analytical precision for all samples, calculated as 905 the standard deviation of an internal mink standard, was 0.11 and $0.12 \%$ for $\delta^{13} \mathrm{C}$ and $\delta^{15} \mathrm{~N}$ values, respectively. Since the $\mathrm{C}: \mathrm{N}$ ratio of prey (littoral prey : mean $=4.60 \pm 0.10 \mathrm{SE}$; 907 pelagic prey : mean $=4.15 \pm 0.12 \mathrm{SE}$ ) were higher than the suggested limits $(3.5$ for aquatic 
908 organisms; Post et al. 2007), the stable isotope values of prey were lipid-corrected before 909 subsequent analyses.

910

911 

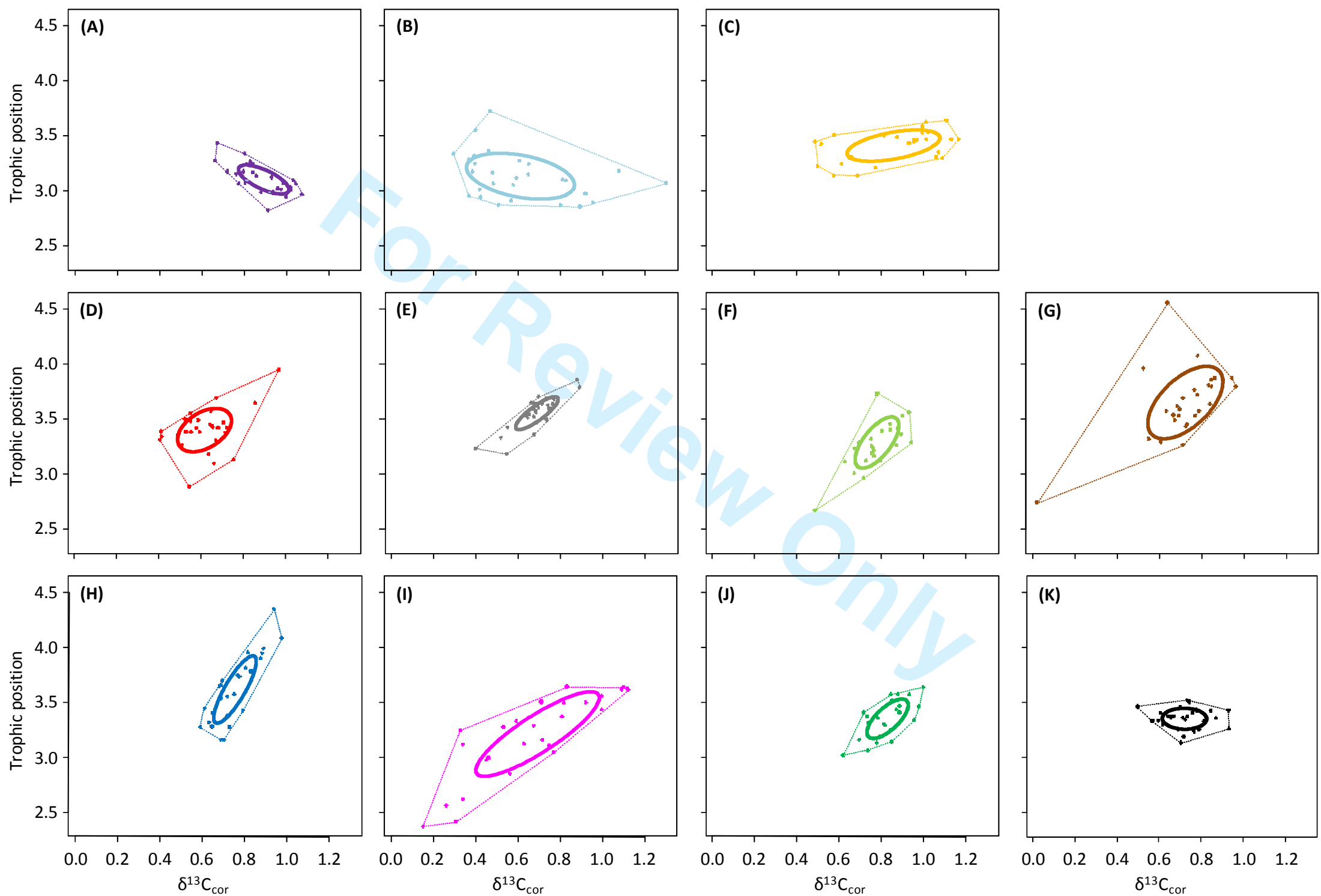
913 Figure $\mathbf{A 1}$ Bi-plots of the trophic position and the corrected $\delta^{13} \mathrm{C}$ values $\left(\delta^{13} \mathrm{C}_{\text {cor }}\right)$ for each 914 population $(\mathrm{A}-\mathrm{K}, \mathrm{n}=11)$. Each dot represents a Lepomis gibbosus individual. For each 915 population, the stable isotope niche is represented by the convex hull area (TA, dashed line; 916 Layman et al. 2007) and the standard ellipse area (SEA, continuous line). Statistical analyses 917 indicate a strong and positive correlation between $\mathrm{SEA}_{\mathrm{b}}$ and TA (Spearman: rho $=0.81, \mathrm{~S}=$ 918 42, 9df, $P=0.004)$.

919

920

921

922

923

924

925

926

927

928

929

930

931

932

933

934

935

936

937 


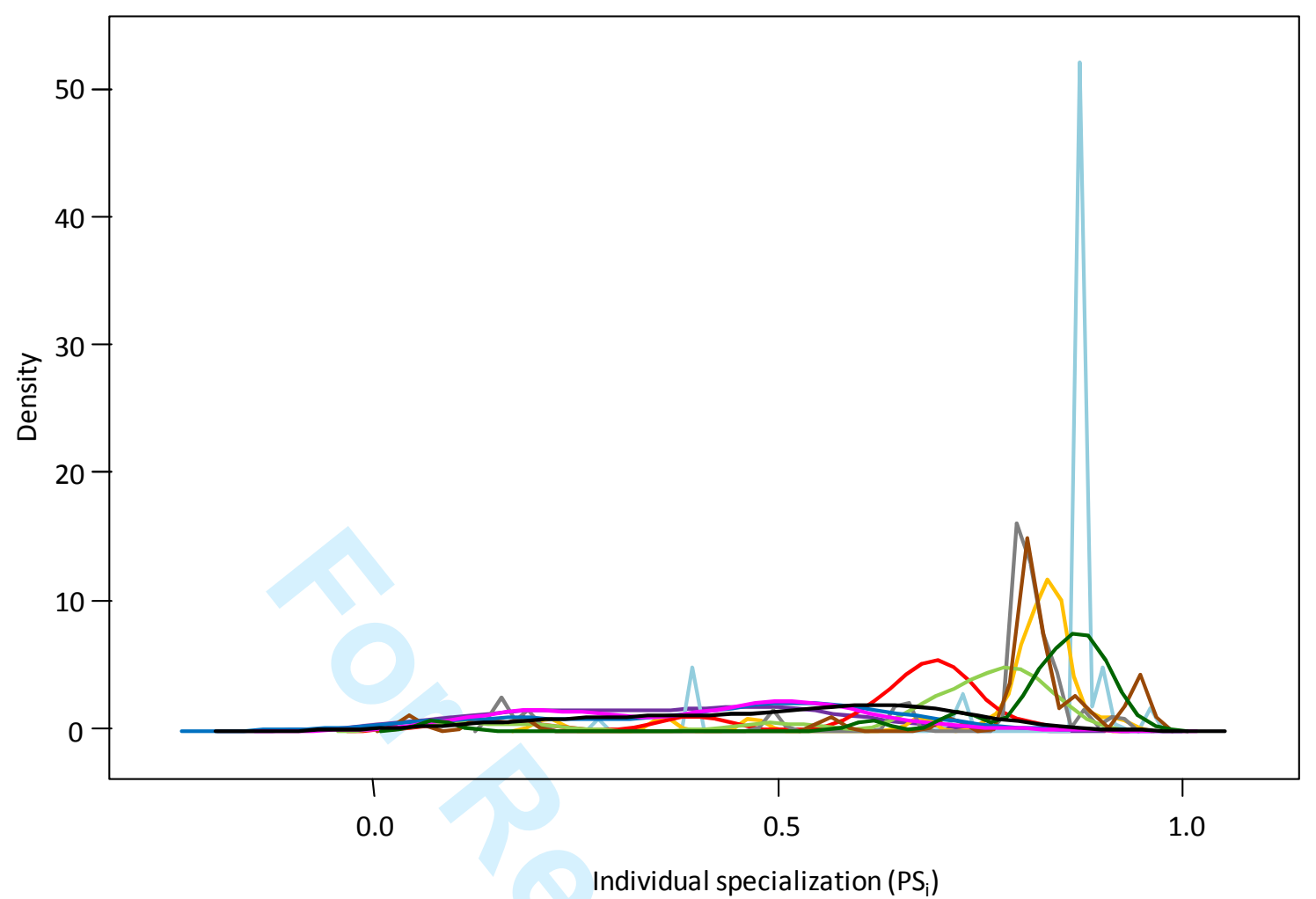

939 Figure A2 Kernel distribution of the individual specialization index $\left(\mathrm{PS}_{\mathrm{i}}\right)$ calculated for the

94011 wild populations of Lepomis gibbosus and based on stomach content analyses. Population 941 colors are indicated in Fig. A1.

942

943

Cited references

944

945

Araújo, M. S. et al. 2011. The ecological causes of individual specialisation. - Ecology Letters

946 14: 948-958.

Boecklen, W. J. et al. 2011. On the use of stable isotopes in trophic Ecology. - Annual Review of Ecology, Evolution, and Systematics 42: 411-440.

Bolnick, D. I. et al. 2002. Measuring individual-level resource specialization. - Ecology 83:

950 2936-2941.

951

Layman, C. A. et al. 2007. Can stable isotope ratios provide for community-wide measures of trophic structure? - Ecology 88: 42-48.

Layman, C. A. et al. 2012. Applying stable isotopes to examine food-web structure: an overview of analytical tools. - Biological Reviews 87: 545-562.

Post, D. M. 2002. Using stable isotopes to estimate trophic position: models, methods, and assumptions. - Ecology 83: 703-718. 
957 Post, D. M. et al. 2007. Getting to the fat of the matter: models, methods and assumptions for 958 dealing with lipids in stable isotope analyses. - Oecologia 152: 179-189.

959 Robinson, B. W. et al. 1993. Ecological and morphological differentiation of pumpkinseed 960 sunfish in lakes without bluegill sunfish. - Evolutionary Ecology 7: 451-464.

961 Svanbäck, R. and Bolnick, D. I. 2007. Intraspecific competition drives increased resource use 962 diversity within a natural population. - Proceedings of the Royal Society B: Biological 963 Sciences 274: 839-844.

964 Zaccarelli, N. et al. 2013. RInSp: an R package for the analysis of individual specialization in 965 resource use. - Methods in Ecology and Evolution 4: 1018-1023. 

the effects of intraspecific variability in nutrient recycling on ecosystem processes

971

972

973

974

975

976

977

978

979

980

981

982

983

984

985

986

987

988

989

990

991

992

993

994

995

996

997

998

999

Appendix B: Experimental protocol of nutrient excretion rates and results of the effects of intraspecific trophic variability on consumers and their subsequent indirect effects on ecosystem functioning.

Nutrient excretion rates of L. gibbosus were quantified in the laboratory following the protocol of Vanni et al. (2002). Two hours after feeding (Glaholt and Vanni 2005), L. gibbosus were placed individually into a translucent plastic bag containing $0.8 \mathrm{~L}$ of spring water and stored in a covered bucket to minimize visual contact and reduce physiological stress during incubation (Whiles et al. 2009). The spring water was low in soluble $\mathrm{N}$ and $\mathrm{P}$ but had similar chemical characteristics, especially $\mathrm{pH}$, to the water used in the experiments. An incubation time of $1 \mathrm{~h} 30$ was used to ensure concentrations of ammonium and phosphorus in the water were above quantification levels (Glaholt and Vanni 2005). Filtered water samples (80 mL filtered using Whatman $\mathrm{GF} / \mathrm{C}$, pore size $1.2 \mu \mathrm{m})$ were analyzed for ammonium $(\mathrm{N}-$ $\mathrm{NH}_{4}{ }^{+}$, hereafter referred to as $\mathrm{N}$ ) and soluble reactive phosphorus (SRP, hereafter referred to as P) concentrations using the phenol-hypochlorite and molybdenum blue methods, respectively, run by an automated continuous-flow colorimetric analyzer (ALPKEM Corporation, Clackamas, OR, U.S.A.). Per capita excretion rates (ER; hereafter referred to as 'excretion rate') of $\mathrm{N}$ and $\mathrm{P}\left(\mu \mathrm{mol}\right.$ ind. ${ }^{-1} \mathrm{~h}^{-1}$ ) were calculated for each individual following Vanni et al. (2002):

where $[\mathrm{I}]_{\text {ind }}$ and $[\mathrm{I}]_{\text {control }}$ are the molar concentration $\left(\mu \mathrm{mol} \mathrm{L} \mathrm{L}^{-1}\right)$ of the element $\mathrm{I}$ observed for fish and control, respectively, $\mathrm{V}$ is the volume (L) of spring bottled water in the plastic bag and $\mathrm{t}$ is the duration of the incubation (hours). At the start of the experiment, initial per capita excretion rates did not differ significantly between treatments (ANOVAs, $P=0.154$ for $\mathrm{N}$ and $P=0.341$ for $\mathrm{P})$. At the end of the experiment, after the final excretion trial, L. gibbosus were euthanized using an overdose of anesthetic and weighted individually $\left(\mathrm{W}_{\mathrm{f}} \pm 0.1 \mathrm{~g}\right)$. 


\section{Cited references}

1001

1002

Glaholt, S. P. and Vanni, M. J. 2005. Ecological responses to simulated benthic-derived nutrient subsidies mediated by omnivorous fish. - Freshwater Biology 50: 1864-1881.

1004

Vanni, M. J. et al. 2002. Stoichiometry of nutrient recycling by vertebrates in a tropical stream: linking species identity and ecosystem processes. - Ecology Letters 5: 285-293.

1006

Whiles, M. R. et al. 2009. Influence of handling stress and fasting on estimates of ammonium 1007 excretion by tadpoles and fish: recommendations for designing excretion experiments. Limnology and Oceanography: Methods 7: 1-7.

1009 